\title{
A Model to Measure Lymphatic Drainage from the Eye
}

by

Min Hui Kim

A thesis submitted in conformity with the requirements for the degree of Master of Science

Graduate Department of Laboratory Medicine and Pathobiology

University of Toronto

(C) Copyright by Min Hui Kim 2011 


\title{
A Model to Measure Lymphatic Drainage from the Eye
}

\author{
Min Hui Kim \\ Degree of Master of Science \\ Graduate department of Laboratory Medicine and Pathobiology \\ University of Toronto
}

2011

\begin{abstract}
Intraocular pressure (IOP) is the most important risk factor for glaucoma development and progression. Most anti-glaucoma treatments aim to lower IOP by enhancing aqueous humor drainage from the eye. Aqueous humor drainage occurs via well-characterized trabecular meshwork (TM) and uveoscleral (UVS) pathways, and the recently described ciliary lymphatics. The relative contribution of the lymphatic pathway to aqueous drainage is not known. We developed a sheep model to quantitatively assess lymphatic drainage along with TM and UVS outflows. Following intracameral injection of ${ }^{125}$ I-bovine serum albumin (BSA), lymph and blood samples were continuously collected. Lymphatic and TM drainage were quantitatively assessed by measuring ${ }^{125}$ I-BSA recovery. This quantitative sheep model enables assessment of relative contributions of lymphatic drainage $(1.64 \% \pm 0.89 \%)$, TM $(68.86 \% \pm 9.27 \%)$ and UVS outflows $(19.87 \% \pm 5.59 \%)$, and may help to better understand the effects of glaucoma agents on outflow pathways.
\end{abstract}




\section{Dedication}

This thesis is dedicated to my parents and little brother for their love, endless support and encouragement. 


\section{Acknowledgments}

This thesis would have not been possible without the support from Dr. Johnston, Dr. Gupta, and Dr. Yücel, my supervisors. I am grateful to have had such wonderful mentors whose encouragement and guidance gave me a continuous source of inspiration and motivation. Thank you, for everything.

I would also like to thank my committee members, Dr Bhagu Bhavnani, and Dr. Isabelle Aubert for their time and advice.

I would like to show my gratitude to Sara Moore who taught me the surgical techniques and helped me with the animal experiments. You made the ' $6 \mathrm{am}$ to $9 \mathrm{pm}$ experiments' enjoyable and memorable. I will miss our days- good and bad.

I would also like to thank members of 'the Johnston lab', for not only being a source of good advice and collaboration, but also for the amount of friendship and warmth. Really, it was more like having another family that I feel very lucky to be a part of. I would also like to thank Dianna Armstrong for her guidance in the search for the thoracic duct.

I would like to thank my family and friends for all their love and support. Thank you for believing in me. Lastly, I would also like to extend my gratitude to WD, for the spark of luck at times when it was most needed. 


\section{Statement}

All surgical procedures and experimentation were performed by members of the lab and myself.

Key contributors are listed below:

Sara Moore: provided insight into the design of and helped perform surgical procedures

Harold Kim: taught me how to perform the BCA assay 


\section{Table of Contents}

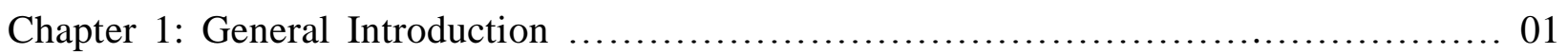

Chapter 2: Is there drainage of aqueous humor into the lymphatic system: Materials and Methods

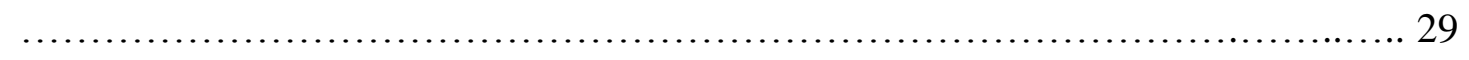

Chapter 3: Is there drainage of aqueous humor into the lymphatic system: Results .............. 47

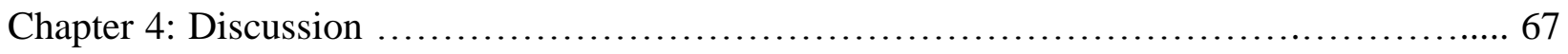

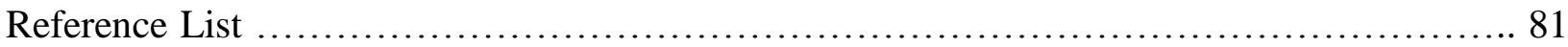




\section{List of Tables}

Table 1 Aqueous Humor Volume of different animal species $\ldots \ldots \ldots \ldots \ldots \ldots \ldots \ldots \ldots . \ldots 15$

Table 2 Uveoscleral flow in different species determined with labeled tracers .......... 17

Table $3 \quad$ Indication of cannulated vessels for each experimental setup ................ 34

Table 4 Distribution of Radioactive Tracer in the Compartments Assessed ............. 63 


\section{List of Figures}

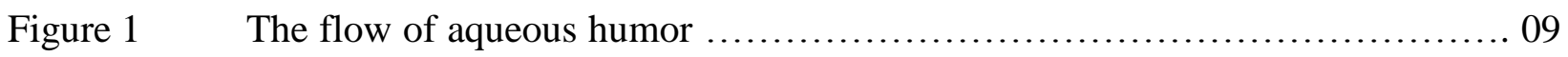

Figure 2 Visualization of a lymphatic channel in the human ciliary body ................ 23

Figure 3 Radioactive tracer recovered in the head and neck lymph nodes

after injection of tracer into the anterior chamber of the eye in sheep ........... 24

Figure 4 Model of the aqueous humor and the two proposed drainage systems, lymphatic and non-lymphatic pathways ............................. 28

Figure $5 \quad$ Surgical preparation in dorsal recumbency position ....................... 32

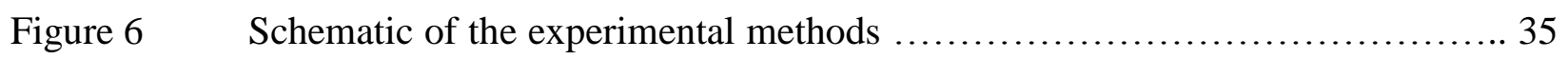

Figure 7 Engineer's model of the aqueous humor including the prescapular lymph

Figure 8 The differing degree of macromolecular restriction

in lymphatic vessels located throughout the body

Figure 9 Example of the calculations for re-filtration correction using numerical values

Figure 10 Representative example of the change in the concentration of radioactivity

over 3 hours post $\mathrm{I}^{125}$-BSA injection ................................. 51

Figure 11 Time course recovery of tracer recovery expressed as a percentage of

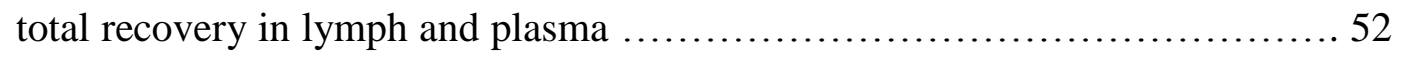

Figure 12 Representative example of the time course recovery of radioactivity ...........54

Figure $13 \quad$ Radioactive tracer recovery in various lymph nodes ....................... 59

Figure 14 Distribution of tracer recovery in the various compartments with

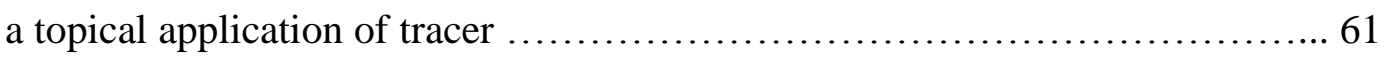

Figure 15 Distribution of tracer recovery before re-filtration corrections ................. 64 
Figure 16 Distribution of tracer recovery after re-filtration corrections (3 hours) ......... 65

Figure 17 Distribution of tracer recovery after re-filtration corrections (5 hours) ......... 66 


\section{CHAPTER 1:}

\section{GENERAL INTRODUCTION}


Chapter 1: General Introduction

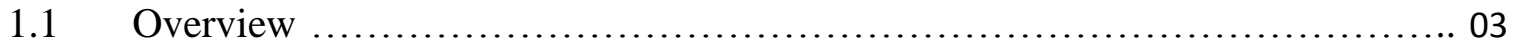

1.2 Background on Glaucoma: in relation to aqueous humor dynamics ............ 03

1.3 Aqueous humor: Composition, Formation and Dynamics ................... 05

1.3.1 Conventional outflow pathway ................................ 08

1.3.2 Unconventional (Uveoscleral) outflow pathway .................... 10

1.4 Treatment Strategies for Glaucoma ...................................... 13

1.5 Quantification of Aqueous Humor Outflow ................................ 14

1.5.1 Conventional outflow quantification ............................ 14

1.5.2 Uveoscleral outflow quantification .............................. 16

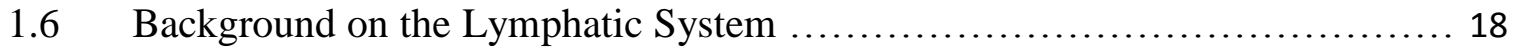

1.7 Analogy of aqueous humor drainage to cerebrospinal fluid drainage

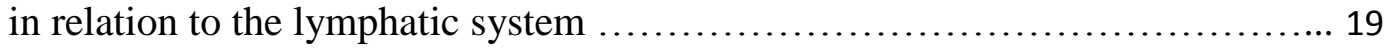

1.8 Evidence for aqueous humor drainage into the lymphatic system .............. 21

1.9 Evidence for the presence of lymphatic channels in the eye $\ldots \ldots \ldots \ldots \ldots \ldots \ldots . \ldots \ldots 22$

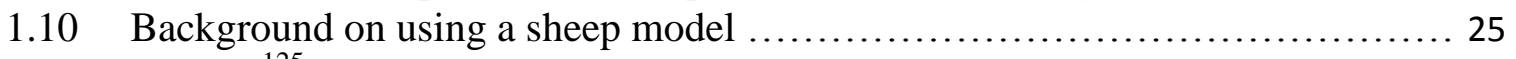

1.11 Use of ${ }^{125} \mathrm{I}$-BSA as a flow marker .................................... 25

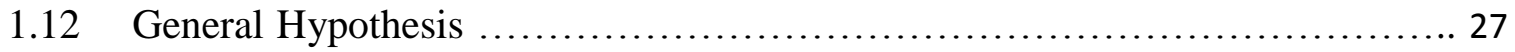




\subsection{Overview}

The lymphatic system is responsible for the removal of interstitial fluid and protein in most tissues and organs; however, the eye has been thought to be devoid of lymphatic vessels. Despite the traditional belief, there is evidence in the literature that supports a link between the lymphatic system and the aqueous humor of the eye. The experimental data seems to warrant a re-examination of aqueous humor dynamics. This may provide a new conceptual foundation to develop novel treatment strategies for disorders that stem from a deregulation in aqueous humor dynamics such as glaucoma.

\subsection{Background on Glaucoma: in relation to aqueous humor dynamics}

Glaucoma is a leading cause of irreversible blindness worldwide, with an estimated 80 million people affected by 2020 (Quigley and Broman, 2006). Half of glaucoma cases are left undiagnosed, even in developed countries, as it is mostly asymptomatic until late in the disease when visual problems become apparent. Glaucoma is defined as a group of diseases that have a common characteristic optic neuropathy with associated visual field loss. The typical structural and functional defects (optic disc damage and visual field loss) have to be sufficiently developed to indicate the death of a substantial number of retinal ganglion cells in the inner retina and loss of their axons in the optic nerve (Johnson et al., 2002). At the optic disc, nerve fibers of retinal ganglion cells pass out of the eye, most often, leaving a central depression or cup that is paler when compared to the rim containing these nerve fibers. Clinicians can determine the cup-to-disc ratio by comparing this cup with the overall disc size. As more retinal ganglion cells and their axons are affected with the progression of glaucoma, the cup-to-disc ratio will increase progressively. The structural changes that are most often recognized is the topographical 
deepening and widening of the cup, due to the loss of retinal ganglion cell axons and deformation of connective tissues supporting the optic disc (Burgoyne et al., 2005).

Elevated intraocular pressure (IOP) is a major risk factor for the development and progression of glaucoma, as it leads to the death of retinal ganglion cells, damage of optic nerve axons, and blindness (Kwon and Fingert, 2009). Current pharmaceutical and surgical treatment strategies aim to preserve visual function by lowering intraocular pressure below a level that is likely to produce further damage to the optic nerve. This is achieved mainly through increasing aqueous humor outflow from the aqueous chamber.

The secretion and dynamics of aqueous humor are critical for the physiological functioning of the eye. In a healthy state, the flow of aqueous humor against resistance generates an average intraocular pressure around 15mmHg (Millar and Kaufman, 1995). IOP is necessary in maintaining the integral shape and optical properties of the globe. Intraocular pressure is determined by three factors: 1) the rate of aqueous humor production by the ciliary epithelium, 2) resistance to aqueous outflow across the trabecular meshwork-Schlemm's canal system, and 3) the level of episcleral venous pressure. Commonly, intraocular pressure in the general population ranges from $10 \mathrm{mmHg}$ to $22 \mathrm{mmHg}$. Generally, increased intraocular pressure is caused by an increased resistance to aqueous humor outflow. Thus, intraocular pressure may be lowered by reducing fluid production, increasing fluid drainage, or a combination of both. 


\subsection{Aqueous humor: Composition, Formation and Dynamics}

Aqueous humor is the fluid occupying the anterior chamber, providing a clear and transparent medium between the cornea and lens. It serves as an important component of the eye's optical system. It functions to nourish the avascular cornea and lens, analogous to blood, providing nutrition, oxygen, and neurotransmitters (Reddy, 1979). It also aids the metabolism of the vitreous and retina by removing excretory products from metabolism from the avascular anterior segment consisting of the lens, cornea, and trabecular meshwork. Additionally, it maintains the shape of the eye and is important for maintaining its optical properties (Sires, 1997). Other proposed functions have been less clearly defined, which includes the delivery of antioxidants, and participation in local immune responses (Krupin and Civan, 1996).

The major components of aqueous humor are organic and inorganic ions, carbohydrates, glutathione, urea, amino acids and proteins, oxygen, carbon dioxide and water. In comparison to plasma, it was shown to be slightly hypertonic in a number of mammalian species (Benham et al., 1938; Kinsey, 1951; Levene, 1958), except for rhesus monkeys, in which no significant differences were observed (Gaasterland et al., 1979). The greatest differences in aqueous humor when compared to plasma are its lower concentration of protein (200 times less) and higher levels of ascorbate (20-50 times higher) (Reiss et al., 1986). The protein composition in aqueous humor is both quantitatively and qualitatively different from that of plasma. Most aqueous humor proteins are intrinsic glycoproteins of the vitreous, which are secretory products of the inner epithelial layer of the ciliary body (Haddad et al., 1991). Anti-oxidant substances found in the aqueous humor such as glutathione and ascorbate, are also important as they protect against light-induced oxidative damage (Krupin and Civan, 1996; Helbig et al., 1989). Also, molecules that are important in extracellular matrix maintenance, such as collagenase, have been found in 
human aqueous humor. These may influence trabecular outflow resistance and, consequently IOP (Vadillo-Ortega et al., 1989).

The ciliary epithelium consists of a pigmented ciliary epithelial cell (PE) layer facing the stroma and a non-pigmented ciliary epithelial cell (NPE) layer facing the posterior chamber of the eye. It is widely accepted that the inner (NPE) layer is the major player in the active transport of substances from the serum to the aqueous humor (Cole, 1977; Krupin et al, 1986; Riley and Kishida, 1986). Three mechanisms are involved in aqueous humor formation: diffusion, ultrafiltration and active secretion (Millar and Kaufman, 1995). Diffusion and ultrafiltration are responsible for the accumulation of plasma ultrafiltrate in the stroma, behind the tight junctions of the NPE layer, from which the posterior chamber aqueous humor is derived (Uusitalo et al., 1973; Gabelt and Kaufman, 2003). These two processes are passive without involvement of active cellular participation. During the diffusion step, lipid soluble substances are transported through the lipid portions of the membrane of the tissues between the capillaries and the posterior chamber in accordance with the concentration gradient across the membrane (Civan and Macknight, 2004). Next, with ultrafiltration, water and water soluble substances flow across fenestrated ciliary capillary endothelia, limited by size and charge, into the ciliary stroma in accordance with the osmotic gradient or hydrostatic pressure (Civan and Macknight, 2004).

The third process, active secretion is thought to be the major contributor in aqueous formation as it is responsible for approximately $80-90 \%$ of the total amount (Gabelt and Kaufman, 2003; Mark, 2009). Active secretion of aqueous humor involves three steps. First, $\mathrm{NaCl}$ ions are transported into the PE cells from the stroma via secondary active transport (paired $\mathrm{Na}^{+} / \mathrm{H}^{+}$and $\mathrm{Cl}^{-} / \mathrm{HCO}^{3-}$ antiports). Next, gap junctions between NPE and PE cells create a functional syncytium allowing for passage of $\mathrm{NaCl}$ ions from PE to NPE. Finally, A3 adenosine receptors regulate the release of $\mathrm{NaCl}$ ions into the posterior chamber. Then, it flows into the 
anterior chamber through the pupil (Civan and Macknight, 2004; Coca-Prados and SanchezTorres, 1998). Active transport produces an osmotic gradient across the ciliary epithelium which promotes the movement of other plasma constituents by ultrafiltration and diffusion (Tornquist et al., 1990)

The rate of aqueous humor turnover is estimated to be $1.0-1.5 \%$ of the anterior chamber volume per minute (Gablet and Kaufman, 2003), which is estimated as $2.4 \pm 0.6 \mu \mathrm{L} / \mathrm{min}$ (mean \pm SD) in human adults (20-83 years, daytime measurement) (Brubaker, 1998). From the anterior chamber, the aqueous humor leaves the anterior chamber of the eye by bulk flow via two pathways at the anterior chamber angle: conventional outflow (pressure-dependent) and another unconventional uveoscleral route (pressure-independent).

It is interesting to note the changes in the rate of aqueous humor production under normal physiological conditions. The rate of aqueous humor inflow undergoes an unequivocal and striking circadian rhythm, as the rate decreases by about $60 \%$ in the afternoon compared to the morning. The rate of aqueous production is also dependant on age, as it decreases with age. Accordingly, outflow (mainly uveoscleral outflow) is also decreased with age (Becker, 1958). A constant IOP can be maintained since both the production and outflow decreases balancing each other. 


\subsubsection{Conventional outflow pathway (Figure 1)}

The conventional outflow pathway is well characterized (Gabelt and Kaufman, 1995): in this route, aqueous humor exits the eye by passing through the trabecular meshwork. The trabecular meshwork has lamellae made of collagen and elastic fibers covered by flat endothelium, forming a sieve-like structure, allowing for the passage of aqueous humor. From here, it drains into the lumen of Schlemm's canal, which serves as a collector channel that leads to the episcleral venous system, allowing for aqueous humor to enter the blood. Fluid movement is via a pressure-dependent transcellular mechanism, frequently associated with paracellular routes such as giant vacuoles and pores acting as one-way valves (Bill and Svedbergh, 1972). These pores range in size from $0.1-3 \mu \mathrm{m}$ in diameter and act as a passageway for particulate materials such as cells, and microspheres along with aqueous humor (Inomata et al., 1972; Epstein and Rohen, 1991). Elevated IOP leads to an increase in the number and size of these vacuoles and an increased volume of outflow via the Schlemm's canal (Grierson and Lee, 1978). After exiting the Schlemm's canal, the aqueous humor enters the aqueous veins and mixes with blood in the episcleral veins where the pressure is approximately $8-10 \mathrm{mmHg}$ (Phelps and Armaly, 1978; Brubaker, 1967). The resistance of the conventional drainage tissue is approdimately $3-4 \mathrm{mmHg} / \mu \mathrm{L} / \mathrm{min}$, resulting in an average IOP of $15.5 \pm 2.6 \mathrm{mmHg}$ (mean \pm SD) for the general population (Schottenstein, 1989). In humans $75 \%$ of the resistance to aqueous humor outflow is attributed to the trabecular meshwork, and the rest beyond the Schlemm's canal (Schottenstein, 1989). Although the major site of resistance within the trabecular meshwork structure has not been well characterized, it is suspected to reside in the juxtacanalicular portion (Ethier et al., 1986; Seiler and Wollensak, 1985). 


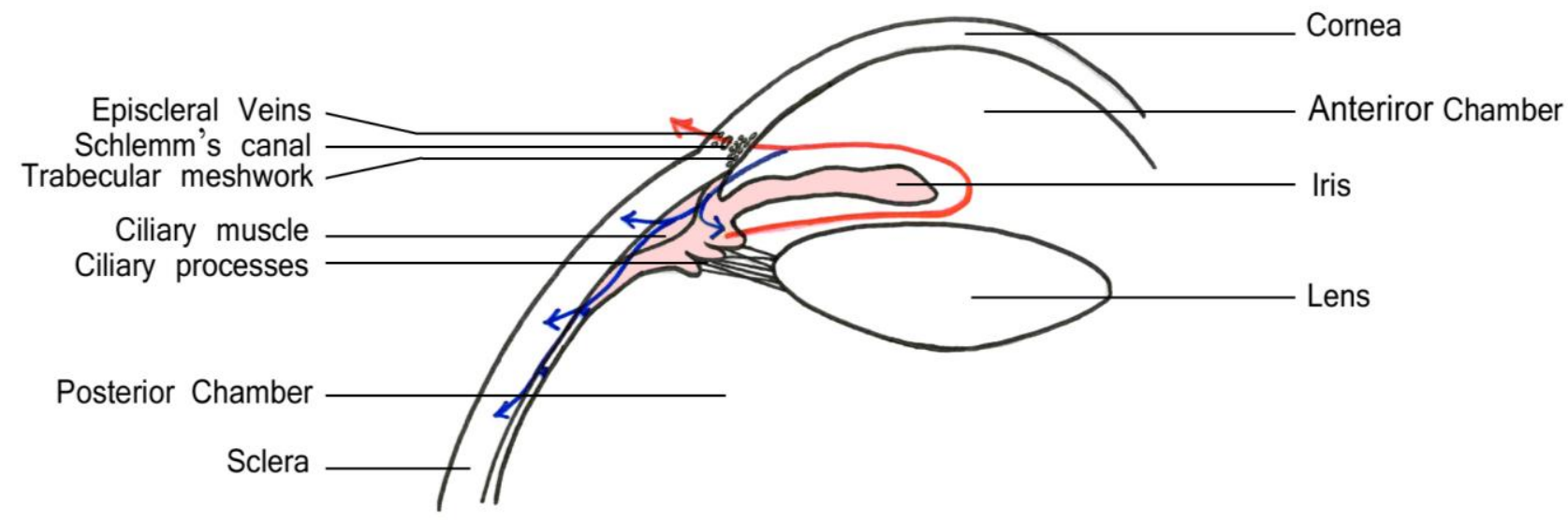

Figure 1. The flow of aqueous humor The basis anatomy of the front of the eye is illustrated in the figure. The anterior chamber of the eye, a compartment between the cornea and the lens, is filled with aqueous humour, a transparent and colorless medium. The aqueous humour nourishes the cornea and lens (devoid of blood vessels) and trabecular meshwork. The aqueous humour is produced by the ciliary epithelium, flows from the posterior chamber around the lens and through the pupil into the anterior chamber. Aqueous humor leaves the anterior chamber of the eye by bulk flow via two pathways at the anterior chamber angle: conventional outflow via the trabecular meshwork and Schlemm's canal (red arrow) and another unconventional uveoscleral route via the ciliary muscle (blue arrow). 


\subsubsection{Unconventional (Uveoscleral) outflow pathway (Figure 1)}

On the other hand, less is known about the unconventional (uveoscleral) outflow pathway (Weinreb, 2000; Alm and Nilsson, 2009). The uveoscleral outflow route was first described in the mid-1960s by Anders Bill. In searching for a suitable tracer to determine aqueous flow, he infused labeled molecules of various sizes into the anterior chamber of monkey eyes and collected the fluid appearing on the anterior sclera (Bill, 1966a). He showed that these tracers, markers of bulk flow of aqueous humor, accumulated in significant quantities in the supraciliary space and its adjacent tissues. Furthermore, Bill calculated that the volume of fluid necessary to carry the observed amount of tracer into such compartments of the eye represented a significant portion of the total outflow of aqueous humor, and named this the 'uveo-scleral' outflow pathway. His data showed consistently that the newly discovered pathway were completely independent to the trabecular outflow pathway.

In this pathway, aqueous humour appears to flow across the base of the iris (the chamber angle formed by the iris and the cornea) through the interstitial tissue in the ciliary body into the suprachoroidal space. The aqueous humour is thought to leave the suprachoroidal space by flowing through the loose connective tissue around the sclera blood vessels and also directly through sclera tissue. In the study of uveoscleral outflow by Bill and Philips (1971), tracer showed aqueous humour flow through the interstitial spaces of the ciliary muscle into the suprachoroidal space, moving into the sclera. It has been assumed that the fluid diffuses into the periocular orbital tissue. However, the final drainage of fluid out of the suprachoroidal space is not clearly understood, and the estimated amount of aqueous humour leaving the eye by the uveoscleral route varies greatly. In humans, the study by Bill and Phillips (1971) showed that 5$25 \%$ of the total outflow is accounted for by uveoscleral drainage, whereas Townsend and Brubaker proposed that approximately $35 \%$ of the total outflow may be via uveoscleral drainage. 
The uveoscleral outflow may be considered analogous to lymphatic drainage of tissue fluid in other organs, since the protein molecules may be drawn in with water and mix with tissue fluid from the ciliary muscle, ciliary processes and choroid (Johnson and Erickson, 2000). In fact, since the ciliary body interstitial tissue fluid is rich in protein, it seems likely that the drainage of this interstitial fluid is performed by the lymphatic system. However, while having a well established role in draining extracellular fluid and solutes in other tissues, the lymphatic system has been thought to be absent in the eye (Bill, 1975). Instead, flow across the sclera has been considered a substitute of lymphatic vessels (Alm and Nillson, 2009) in the removal of protein from the eye as the vessels of the choroid and the ciliary processes are unusually permeable, allowing passage of large proteins into the extravascular space.

Unlike conventional outflow, where flow increases linearly with IOP (within the physiologically normal range), uveoscleral flow is relatively pressure-independent. Because the rate of uveoscleral flow does not depend on IOP to the same extent as conventional outflow, it is often referred to as being 'pressure-independent' (Nilsson and Bill, 1994). As mentioned earlier, the main resistance is imposed by the trabecular meshwork in the conventional outflow pathway. The pressure gradients are different in the unconventional outflow pathway. Because the sclera offers little resistance to flow, and the choroidal vessels are able to absorb the small amount of aqueous humor delivered, the main resistance is most likely be to within the ciliary muscle. As mentioned before, in the healthy aging eye, there is a reduction in drainage through the uveoscleral outflow pathway. When this is considered with the age-related changes observed within the ciliary muscle, the above hypothesis, of uveoscleral flow being pressure independent, is strengthened. Although the uveoscleral drainage pathway is relatively unaffected with IOP changes, the relationship does not hold during extreme conditions. When IOP is bellow $4 \mathrm{mmHg}$ (Bill, 1967a), uveoscleral flow is much reduced, and during cyclodialysis - which will remove 
almost all resistance created by the ciliary body - the uveoscleral flow increases greatly. The effect of cyclodialysis was shown in rabbits, where the portion of aqueous outflow in relation to total outflow increased from 3 to 54\% (Bill, 1966b) and in monkeys (Toris and Pedersen, 1985). It was also shown that ciliary muscle contraction could affect uveoscleral flow, further supporting this theory (Bill, 1967b). 


\subsection{Treatment Strategies for Glaucoma}

Treatment strategies for glaucoma focus on reducing IOP through medical or surgical therapy. The major classes of medications available include $\alpha$-adrenergic agonists, $\beta$-adrenergic antagonists ( $\beta$-blockers), carbonic anhydrase inhibitors, cholinergic and prostaglandin analogs (PGAs). Topical and systemic carbonic anhydrase inhibitors decrease the production of aqueous humor by the ciliary body epithelial cells, while prostaglandin agonists increase uveoscleral outflow (remodeling of the ciliary muscle has been proposed as a mechanism). Other medications such as adrenergic agonists decrease outflow resistance through mechanisms that are not completely understood. When pharmacological therapies do not result in an adequate lowering of IOP, surgical therapy may be implemented. Current surgical therapies include trabeculectomy, glaucoma drainage implants and glaucoma shunts (penetrate trabecular meshwork and cannulate Schlemm's canal or create a path through the sclera wall) to bypass outflow resistance by shunting aqueous humor through or around the trabecular meshwork.

Understanding the dynamics of aqueous humor is critical in gaining insight into, and developing novel treatment strategies for glaucoma. 


\subsection{Quantification of Aqueous Humor Outflow}

The volume of aqueous humor in the anterior chamber is relatively small. To give perspective of magnitude, the anterior chamber volumes for a variety of different species that have been measured are summarized in Table 1.

\subsubsection{Conventional outflow quantification}

As mentioned before, the majority of aqueous humor outflow, for both primates and humans, occurs via a series of specialized channels comprised of the trabecular meshwork, the Schlemm's canal, and the collector of channels that span the sclera. This system of channels empties into the episcleral plexus of veins in the region of the limbus. This pathway has been described in detailed through histology, injection modeling, and direct slit lamp observation of aqueous humor in the living eye. In early experiments, the flow was determined by injecting macromolecules (including radioactive tracers) directly into the anterior chamber, and from analyzing how the tracer was diluted from post injection (Becker, 1962; O'Rourke and Macri, 1970). Later on, methods that had fewer potentially damaging side effects were developed. For example, fluorescein is a tracer that does not require injection into the eye, and is still readily measureable in the anterior chamber. Goldman was first to use fluorescein as a tracer to study aqueous humor flow (1951). Fluorescein was injected systemically and the appearance and disappearance of the tracer in the anterior chamber was measured to determine the flow rate of aqueous humor. However, due the complexity of this approach in administering fluorescein and also in interpretation of the measurements, the method has not been used regularly. 
Table 1. Aqueous Humor Volume of different animal species

\begin{tabular}{lll}
\hline Species & & \\
\hline Rhesus Monkey & $177.0 \pm 8.88 \mu \mathrm{L}$ & Cevario and Macri, 1974 \\
& $175.26 \pm 4.91 \mu \mathrm{L}$ & \\
Cynomolgus Monkey & $134 \pm 5 \mu \mathrm{L}$ & Pederson et al., 1978 \\
Rabbits & $101.8 \pm 4.2 \mu \mathrm{L}$ & Greenbaum et al., 1985 \\
Dogs (Beagles) & $287 \mu \mathrm{L}$ & Conrad and Robinson, 2006 \\
Cats & $325-400 \mu \mathrm{L}$ & Toris et al., 2006 \\
Mouse (NIH Swiss White) & $553 \pm 80 \mu \mathrm{L}$ & Macri et al., 1965 \\
Deer & $1400 \pm 90.5 \mu \mathrm{L}$ & Aihara et al., 2003 \\
Domestic Pig & $300 \mu \mathrm{L}$ & Colasanti, 1984 \\
Humans & $209 \pm 37 \mu \mathrm{L}(19-56$ yrs $)$ & McMenamin et al., 1991 \\
& $174 \mu \mathrm{L}$ & Johnson et al., 1978 \\
& $247 \pm 39 \mu \mathrm{L}(20-30$ yrs $)$ & Yablonski et al., 1978 \\
& $160 \pm 39 \mu \mathrm{L}(>60$ yrs $)$ & Toris et al., 1999 \\
& $144 \pm 5.04 \mu \mathrm{L}$ & Kondo et al., 1986 \\
& $171.1 \pm 39.6 \mu \mathrm{L}$ & Labiris et al., 2009 \\
\hline
\end{tabular}




\subsubsection{Uveoscleral outflow quantification}

Uveoscleral outflow has been studied in various animal species, using labeled tracers (Table 2). In comparing the different species, the volume of uveoscleral outflow was found to be large in monkeys, but small in rabbit and cats (Bill, 1966b; Wang et al., 1993; Wang et al., 1999). Because uveoscleral flow cannot be sampled from a single outlet, an indirect method is required. In the initial studies, tracer was removed from the anterior chamber by rinsing with a mock aqueous humor solution, and the animals were sacrificed. After, the amount of tracer remaining in the ocular tissues was determined. As the mean concentration of the tracer in the anterior chamber was determined, it is then possible to calculate the rate of uveoscleral flow as the amount of tracer in the tissue divided by the mean concentration of the tracer in the anterior chamber during the experiment (Bill, 1965; Bill and Hellsing, 1965).

In the mid $20^{\text {th }}$ century, in an attempt to characterize the dynamics of aqueous humor circulation, investigators have developed mathematical approaches. Using the relationship between the four parameters of aqueous humor dynamics, it also led to a development of methods of assessing aqueous humor outflow in in vivo settings. Grant developed a method of measuring the facility of aqueous humor outflow using a tonometer (Grant, 1950), and Goldman described methods for measuring three of its parameters; intraocular pressure, aqueous humor formation, and episcleral venous pressure (Goldman, 1951). The steady state equations used in such methods contained four parameters, and fourth could be calculated when the rest of the parameters could be determined via direct measurement. Although clinical methods were available for measuring all four parameters, the validity and accuracy of episcleral venous pressure has always been an issue. The Goldmann's equation does not always balance exactly when the four parameters were measured. Such inconsistence can be attributed to measurement errors or other sources that was later added to the Goldman's equation: 
Table 2. Uveoscleral flow in different species determined with labeled tracers (Alm and Nilsson, 2009)

\begin{tabular}{llll}
\hline Species & Fu $(\mu \mathrm{l} / \mathrm{min})$ & \% of $F_{\text {in }}$ & Reference \\
\hline Cynomolgus monkey & 0.96 & 55 & Bill (1971) \\
Vervet monkey & 0.65 & 38 & Bill (1971) \\
Cat & 0.36 & 3 & Bill (1966c) \\
Rabbit (albino) & $0.11-0.26$ & $3-8$ & Bill (1966d), \\
Dog (beagle) & n.d. & 15 & Poyer et al. (1992) \\
\hline
\end{tabular}

n.d., not determined.

Fu: Uveoscleral outflow

Fin: Aqueous outflow 
$\mathrm{F}=\left(\mathrm{P}_{\mathrm{i}}-\mathrm{P}_{\mathrm{e}}\right) \times \mathrm{C}+\mathrm{U}$

Where F: aqueous outflow, $\mathrm{P}_{\mathrm{i}}$ : IOP, $\mathrm{P}_{\mathrm{e}}$ : episcleral venous pressure, C: facility of trabecular meshwork outflow, U: uveoscleral outflow.

Unfortunately, it is not clear whether the expanded equation is valid, as no method for measuring either uveoscleral outflow has been developed for the human eye. Current understanding of the quantitative aspects of uveoscleral flow in humans is derived from animal experiments and from mathematical calculations of the modified Goldmann equation. In animal experiments, uveoscleral outflow is measured by injecting a labeled molecule into the anterior chamber, and by measuring the levels of the labeled molecule in the ocular tissues of the uveoscleral pathway which includes the ciliary body, iris, choroid, and sclera. Various macromolecules have been used as tracers, including radioactive iodine labeled bovine serum albumin and fluorescein.

\subsection{Background on the Lymphatic System}

The lymphatic system is a distinctive circulatory system composed of lymphatic vessels, lymph, and lymph nodes. The small initial vessels coalesce into larger collecting ducts and ultimately empty into the blood vasculature via the thoracic lymph duct. It is a critical component of the plasma - tissue fluid - lymph circulation, and is also critical to immune surveillance. It is distinctive to the blood vasculature in that the basement membrane is discontinuous, has open endothelial junctions, anchoring filaments, and intrinsic contractility. Lymph is a ultrafiltrate of plasma and is formed during the uptake of interstitial fluid and solutes at the absorbing end of the system, at the initial vessels. The initial lymphatics are composed of overlapping endothelial cells, which may be attached to the interstitium by anchoring filaments. The gap between the endothelial cells allow for the movement of water, protein and solutes. The 
initial vessels coalesce into larger collecting ducts. The collecting ducts can be described as being pre- and post- nodal ducts, depending on whether they lead into or away from a lymph node. The vessels can be further broken down into functional units, called lymphangions, arranged in series. Valves are located along the system to prevent backflow. The collecting ducts eventually empty into the vascular system at the junction of the left subclavian vein and the internal jugular vein via the thoracic duct. Along with its well-known role in immune functioning, the lymphatic system is also critical in maintaining fluid and protein homeostasis.

In addition to studies of lymph formation, composition and flow using lymphatic cannulation techniques, recent development in highly specific lymphatic markers such as vascular endothelial growth factor receptor 3 (VEGFR3), prospero homeobox protein 1 (prox1), podoplanin, and lymphatic endothelial hyaluronan receptor-1 (lymphatic vessel endothelium-1) (LYVE-1) has made possible for further advances in the field.

\subsection{Analogy of aqueous humor drainage to cerebrospinal fluid drainage in relation to the lymphatic system}

It has been assumed by many that the aqueous humor is cleared directly into the local venous system. Surprisingly, this is highly reminiscent of similar entrenched views in the field of cerebrospinal fluid (CSF) drainage. There are many analogies between the clearance of fluid from the anterior chamber of the eye and the drainage of cerebrospinal fluid (CSF). In the latter case, despite a literature that 'enshrined' the cranial venous hypothesis for CSF uptake, recent data indicates that the lymphatic system has a major role in CSF absorption.

Lymphatic vessels have a well-established role in the drainage of extracellular fluid and solutes. However, two organs in which this circulatory system was believed to have no role in interstitial clearance were the brain and the eye. It is now clear however, that the lymphatic 
system has a major role in CSF absorption (Mollanji et al., 2001; Johnston et al., 2004; Papaicononou et al., 2004; Johnston et al., 2005). In the brain, CSF is produced by the choroid plexus and circulates from the ventricles to the subarachnoid space. In the eye, the ciliary epithelium is somewhat analogous to the choroid plexus and the anterior chamber is a serous cavity not unlike the intracerebral ventricular system. A role for the lymphatic circulation in CSF absorption was ignored until recently when Johnston developed quantitative methods to estimate this parameter (Boulton et al., 1997, 1998; Mollanji et al., 2001). The data demonstrated unequivocally, that the lymphatics were important in CSF absorption from the subarachnoid compartment. The data casts some doubt as to the role of the arachnoid granulations and villi in the process (Papaiconomou et al., 2002; Zakharov et al., 2004).

In the case of the eye, the data is less clear in part, because there have been no systematic attempts to test whether the lymphatics have a role in extracellular fluid clearance. Nonetheless, the published literature is consistent with the view that lymphatic vessels have some role in the drainage of extracellular fluid, at least from select portions of the eye and peri-ocular tissues. The injection of Evans blue dye or Microfil into the palpebral conjunctiva of Koalas revealed draining lymphatic vessels that lead to a variety of lymph nodes including the mandibular nodes and nodes adjacent to the parotid gland (Kempster et al., 2002). Similarly, in rabbits, ${ }^{99} \mathrm{mTc}-$ micro-colloid was found in the mandibular and deep cervical lymph nodes after injection into the subconjunctival space (Gruntzig et al., 1978a). In addition, there is evidence for lymphatic drainage of radioactive tracers from the vascularized cornea (Collin, 1970), from the retrobulbar space (Gruntzig et al., 1977) and from the vitreous humor (Gruntzig et al., 1978b) leading to tracer accumulation in the cervical nodes. 
Along these lines, the methods developed to assess CSF transport may be helpful in assessing the importance of the lymphatic circulation in the clearance of fluid from the anterior chamber of the eye.

\subsection{Evidence for aqueous humor drainage into the lymphatic system}

The literature contains some largely qualitative evidence supporting a lymphatic function in aqueous humor drainage suggesting a link between the eye and the lymphatic system. Fluorescein labeled dextran was injected into the anterior chamber of rabbits were found to enter the aqueous plexus and were observed in vessels leading away from this structure (Cole and Monro, 1976). However, the authors made no comment on the nature of the vessels assuming probably that they were of venous origin. This may not be the case. The strongest evidence for a link between the anterior chamber and the cervical lymphatic system comes from studies in which a tracer is introduced into the aqueous humor and its recovery in the lymphoid tissues is monitored. In this regard, Gruntzig and colleagues observed that various radioactive substances introduced into the aqueous humor could be found in the superficial cervical lymph nodes (Gruntzig et al., 1977, 1979). Since radioactivity was also noted in the retrobulbar space in these experiments, the authors speculated that some form of anatomical link existed between the anterior chamber and the retrobulbar tissues. It should be noted however, that there is some contradictory evidence. In rabbits and cats, no radioactivity was observed in the cervical lymph within 6 hours after injection of radioactive albumin into the aqueous humor (Bradbury and Cole, 1980). In addition, the expression of 5' nucleotidase (a putative lymphatic endothelial marker) was not observed in any part of the aqueous outflow pathway (Krohn and Rodahl, 2002) 


\subsection{Evidence for the presence of lymphatic channels in the eye}

Recent emergence of specific lymphatic endothelial markers have led to studies that directly challenge the assumption that no lymphatic vessels exist in the eye. These specific markers include podoplanin, a transmembrane mucin-type glycoprotein, specifically detected with D2-40 antibody (Kahn and Marks, 2002) and lymphatic endothelial hyaluronan receptor-1 (LYVE-1). D2-40 is a novel monoclonal antibody that reacts with a fixation-resistant epitope specific for lymphatic endothelium. It is able to selectively mark lymphatic endothelial cells in normal tissues and various tumour types. LYVE-1 is a hyaluronan receptor expressed on lymphatic endothelial cells (Banerji et al., 1999). Several experiments have been conducted using these novel markers to identify lymphatic vessels in the eye. Yücel and colleagues were able to detect lymphatic vessels in the ciliary body using D2-40 (Figure 2) in humans, and in the

sheep ciliary body, the results were confirmed with LYVE-1 markers. This strongly suggests that lymphatics are present in the eye (Yücel et al., 2009).

Furthermore, when radioactive tracer was injected into the anterior chamber of the eyes in sheep, radioactivity was measured in the head and neck lymph nodes, suggesting that the drainage of aqueous humor may occur via lymphatic vessels (Figure 3). Additionally, fluorescent nanospheres were injected into the anterior chamber of sheep and were found to localize in the lumen of LYVE-1 positive lymphatic channels in the ciliary body. This suggests the roles of these channels in transporting particles from the anterior chamber (Yücel et al., 2009). 


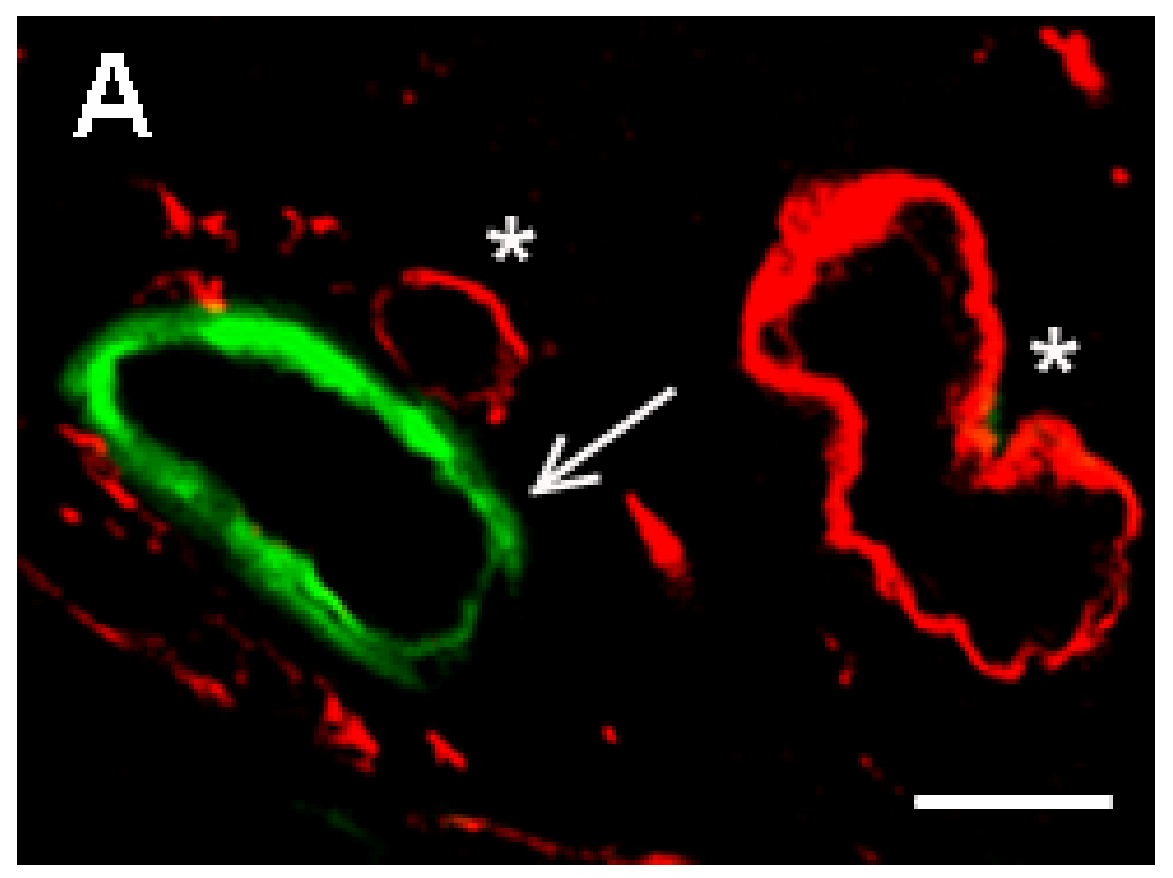

Figure 2. Visualization of a lymphatic channel in the human ciliary body Human ciliary body section with double labeling shows a D2-40 positive lymphatic vessel (in green indicated with arrow) with a central lumen that is distinct from a collagen IV-positive blood vessel (in red indicated with asterisk. Calibration bars indicate 10nm. (Yücel et al., 2009) 


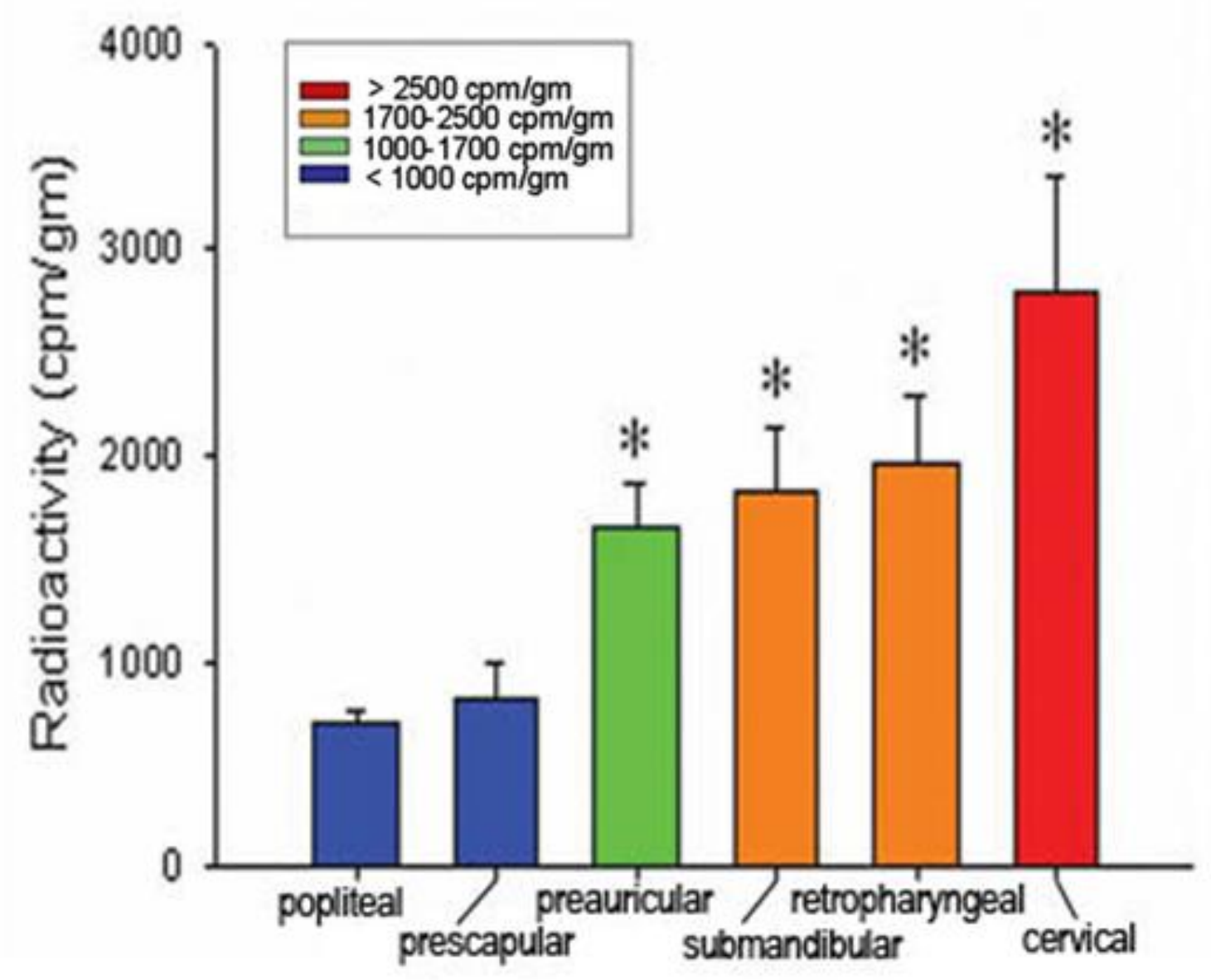

Figure 3. Radioactive tracer recovered in the head and neck lymph nodes after injection of tracer into the anterior chamber of the eye in sheep The histogram shows radioactivity counts in regional lymph nodes compared to the reference popliteal site, 4 hours post intracameral tracer injection. There were significant differences in radioactivity counts in submandibular, retropharyngeal, preauricular and cervical nodes compared to popliteal site by one-way repeated ANOVA measures followed by single degree of freedom contrasts for each site $(\mathrm{P}<0.05)$ (Yücel et al., 2009) 


\subsection{Background on using a sheep model}

A sheep model is the focus of the experiments laid out in this study. The commonly used rodent models in biomedical research are challenging due to their small size. On the other hand, sheep offer significant advantages to this study because of a well-developed lymphatic system, with relatively large lymphatic vessels compared to other animal models. This makes it possible to manipulate and cannulate individual vessels, allowing for studies that involve assessing tracer recovery in lymph. A sheep model has been used extensively in the CSF drainage study mentioned earlier, allowing for an adaptations of certain techniques into the current study. In the current study, techniques of previous tracer studies done in sheep from Johnston's group were utilized in conjunction with the injection of tracer into the anterior chamber, which have been used as early as the 1960s (Bill and Hellsing, 1965). In these experiments, intracamerally injected tracer recovery was monitored in plasma to estimate the amount of aqueous humor drainage via the trabecular meshwork-Schlemm's canal pathway. The quantity of tracer found in the uveoscleral eye tissue (iris, ciliary body, choroid, sclera) was measured to estimate the amount of aqueous humor drainage via the uveoscleral pathway. Second, aqueous secretion physiology (Gerometta et al., 2005) and trabecular meshwork anatomy (Simoens et al., 1996; Guyomard et al., 2008) are similar in sheep and primates. Finally, a recently developed sheep model of glaucoma (Gerometta et al., 2009) has already been used for developing and testing therapeutics (Gerometta et al., 2010). 


\subsection{Use of ${ }^{125}$ I-BSA as a flow marker}

The use of albumin and other proteins as a flow marker is well established in the literature (Flessner et al. 1984; 1985; 1992, Boulton et al., 1997; 1998). Our model assumes that the tracer concentration is not altered by absorption into the initial lymphatic vessels. There is no evidence that such an effect occurs (Adair and Guyton, 1985). However, once the tracer is in lymph, it can be concentrated or diluted on passage through lymph nodes depending on the balance of hydrostatic and oncotic forces. Nonetheless, the dilution or concentration of the tracer on passage through the node would not affect our model since the critical issue is the total mass of tracer (product of flow and concentration), which would be unaffected. Therefore, the collection of post-nodal lymph will not compromise the flow estimates.

Macrophages can be found in most tissues and there is the possibility that these cells could 'digest' some of the tracer. However, the phagocytosis of injected albumin likely represents a small loss of the protein over the short duration of our experiment. If any such loss occurs, it would have the effect of underestimating aqueous humor transport. It is important to note that all radioactivity measured will be expressed as protein associated counts since the samples will be TCA precipitated to determine protein-bound and free radioactivity $(<2 \%$ preinjection). 


\subsection{General Hypothesis}

Absorption of aqueous humor from the anterior chamber of the eye occurs in part, via transport into the lymphatic circulatory system. It is predicted that aqueous humor will be drained by the unconventional pathway directly into a network of lymphatic vessels located within the globe. If this is the case, radioactive tracer introduced to the anterior chamber should be found in samples of lymph collected from the cervical lymphatic vessels and possibly the thoracic duct (Figure 4).

The goal of the current study was to take such findings a step further and quantitatively assess lymphatic, trabecular and uveoscleral contributions in aqueous humor outflow in sheep. Tracer methodologies used to quantify lymphatic drainage in non-ocular tissues (Boulton et al., 1998) and radiolabeled albumin used to study trabecular and uveoscleral drainage (Bill, 1965; Gabelt and Kaufman, 1989) were used. 


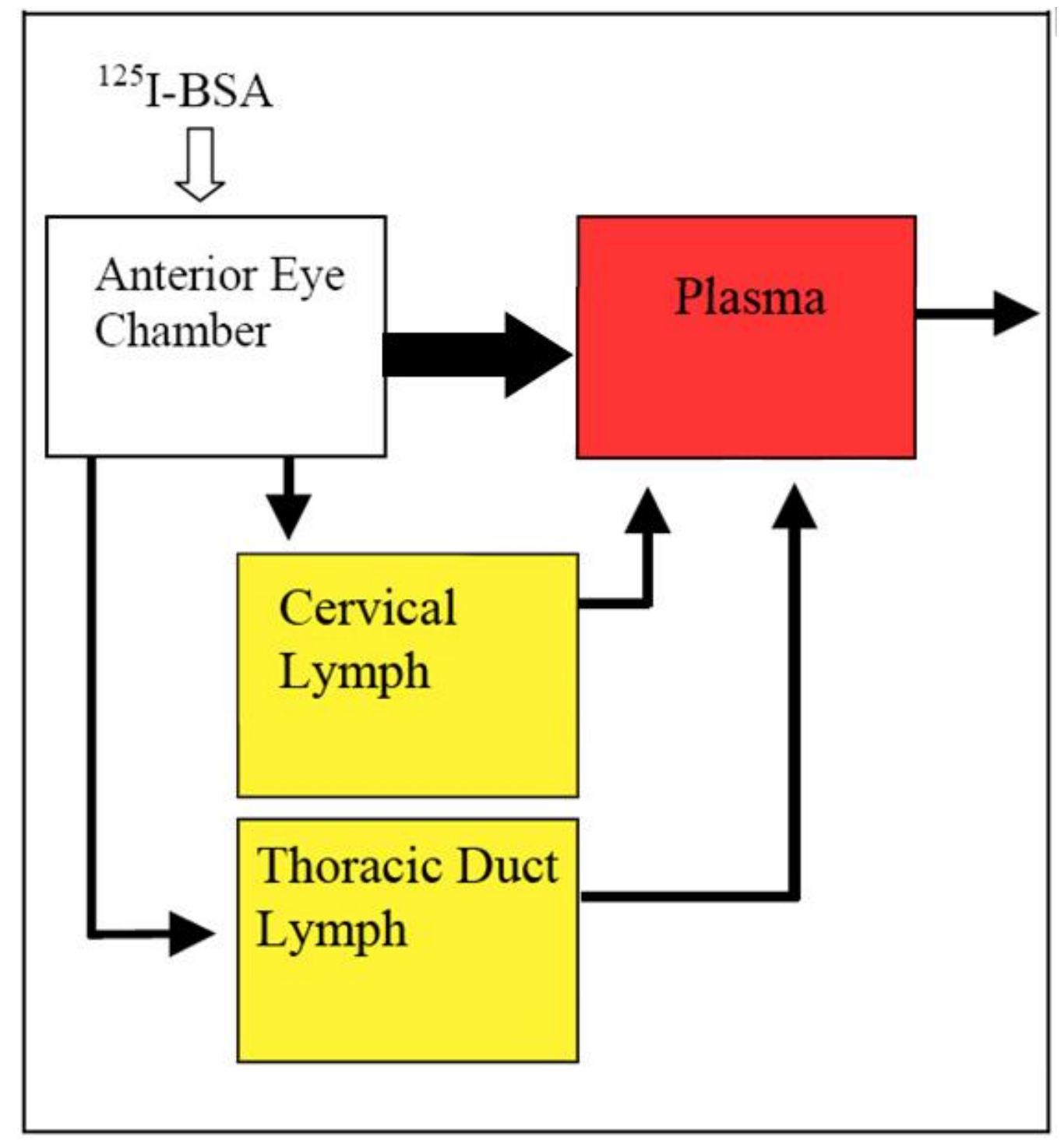

Figure 4. Model of the aqueous humor and the two proposed drainage systems, lymphatic and non-lymphatic pathways Radioactive albumin is injected into the anterior chamber of both eyes. The anterior chamber is assumed to be well mixed From the anterior chamber, there is presumably, some non-lymphatic transfer of the protein into the veins. There is also drainage to the cervical lymphatics and (possibly) to the thoracic duct. The lymphatics, which drain the anterior chamber, join with drainage from the cervical tissues to form the cervical tissue lymph. The cervical lymph flow rate and the concentration of tracer in this lymph can be measured directly. To ensure that all possible lymphatic drainage is accounted for, it is assumed that some lymph from the eye transports via other pathways to reach the thoracic duct. The thoracic duct flow rate and the concentration of tracer in this lymph can be measured directly. 


\section{CHAPTER 2:}

\section{IS THERE DRAINAGE OF AQUEOUS HUMOR INTO THE LYMPHTIC SYSTEM: MATERIALS AND METHODS}


Chapter 2: Is there drainage of aqueous humor into the lymphatic system: Materials and Methods

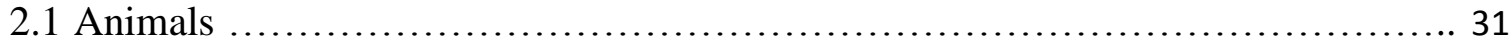

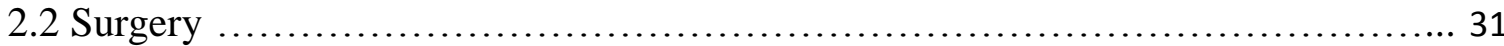

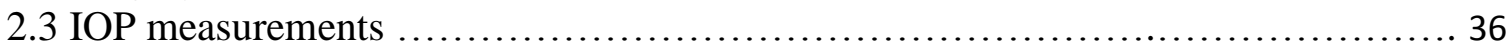

2.4 Collection of ${ }^{125} \mathrm{I}$-BSA in lymph and plasma samples ........................ 36

2.5 Post-mortem harvesting of ocular and periocular tissues .......................... 37

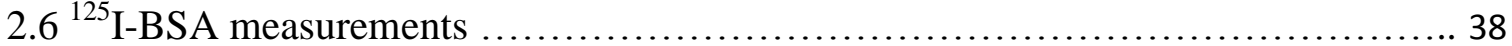

2.6.1 Lymph ${ }^{125}$ I-BSA measurements and correction for re-filtration ..............38

2.6.2 Plasma ${ }^{125}$ I-BSA measurements and correction for re-filtration .............44

2.7 Impact of tracer drainage from conjunctiva-lacrimal ductal pathway .............. 46 


\subsection{Animals}

Sixteen randomly bred sheep (25-35 kg; Hutchison Farms, ON, Canada) were used in experiments approved by the institutional animal care committee and conforming to guidelines set by the Canadian Council on Animal Care and the Animals for Research Act of Ontario.

Using a sheep model offers several advantages in this study. As mentioned earlier, the lymphatic vessels in a sheep are relatively large compared to other animal models, making it possible to cannulate individual. Also, aqueous secretion physiology (Gerometta et al., 2005) and trabecular meshwork anatomy (Simoens et al., 1996; Guyomard et al., 2008) are similar in sheep and primates. Finally, a recently developed sheep model of glaucoma (Gerometta et al., 2009) has already been used for developing and testing therapeutics (Gerometta et al., 2010).

\subsection{Surgery}

Sheep were anesthetized by induction with $20 \mathrm{~mL}$ thiopental sodium (Hospira Healthcare Corp., Vaughan, ON, Canada) administered intravenously; deep general anesthesia was maintained under isoflurane (Abbott Laboratories, Montreal, QC, Canada). A heating pad was placed under the belly of anesthetized animals, and percentage $\mathrm{HbO}_{2}$ and heart rate continuously monitored using a pulse oximeter (Benson Medical Instruments, Minneapolis, MN). Catheter placement was performed with animals in a dorsal recumbent position (Figure 5). Cervical lymphatic vessels and the thoracic lymphatic duct, at its junction with the venous system, were cannulated using 1.5- and 1.7-mm clear vinyl tubes (Dural Plastics Eng. Pty Ltd., Dural, NSW, Australia), respectively, as previously described (Boulton, et al., 1998). Lymph was collected into 16 x $100 \mathrm{~mm}$ polystyrene tubes (Diamed Lab Supplies Inc., ON, Canada) containing about 


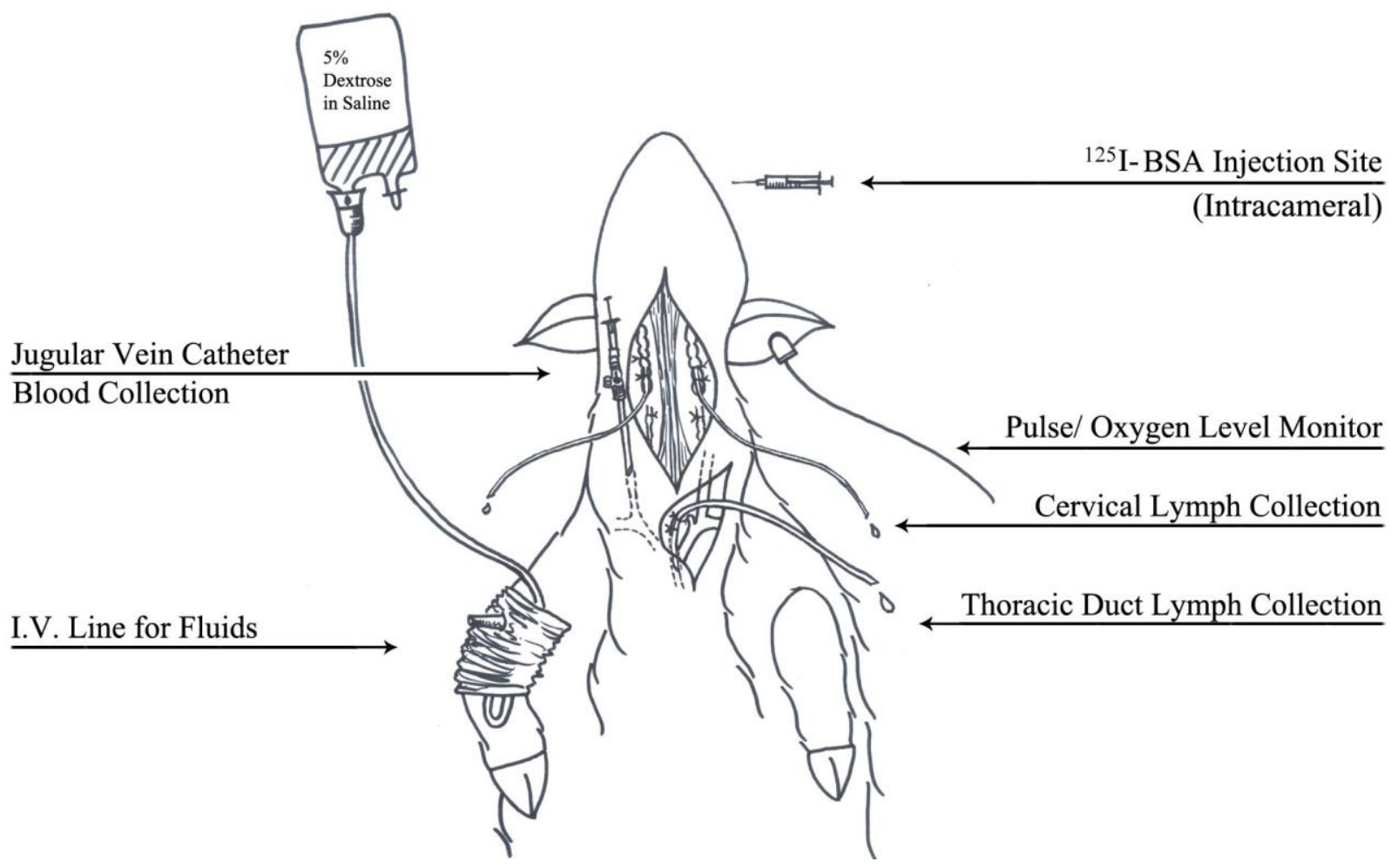

Figure 5. Surgical preparation in dorsal recumbency position. When the surgical procedures were complete, the sheep was placed in the sternal recumbency position and the head was placed in a headstand with its chin resting on a bar. ${ }^{125}$ I-BSA was injected directly into the anterior chamber. 
$15 \mathrm{U} / \mathrm{mL}$ heparin (Pharmaceutical Partners of Canada Inc, ON, Canada) to prevent coagulation; outflow ends of all lymphatic catheters were positioned approximately level with the sheep's olecranon and left atrium. Lymph samples were checked for blood contamination; contaminated samples were excluded. In control experiments, right pre-scapular lymphatic vessels were cannulated and lymph collected to calculate re-filtration from plasma to lymph. In eight sheep (ID numbers 1, 2, 3, 4, 6, 8, 9, and 10), distinct right and left cervical vessels were visible and cannulated. In two sheep (ID numbers 5 and 7), distinct right and left cervical vessels could not be identified, and multiple cervical vessels that were too small to cannulate were ligated with non-absorbable silk suture (Covidien Syneture, Norwalk, CT) to prevent transport of intracamerally injected tracer to plasma via this route. For blood sampling, a right jugular vein line (Argon Medical Devices Inc, Athens, TX) connected to a four-way stop cock (Smiths Medical ASD Inc, Dublin, OH) was inserted into the right jugular vein. To replenish fluids lost from sampling and salivation, an intravenous line was placed in a cephalic vein for infusion of $5 \%$ dextrose saline infusion $(10 \mathrm{~mL} / \mathrm{kg} /$ hour $)$. The methodology is shown in Figure 6, and Figure 5 is a diagram of the experimental set up. Table 3 describes which vessels were cannulated in the 12 animals in which the surgical procedure was carried out. 
Table 3. Indication of cannulated vessels for each experimental set up

\begin{tabular}{|l|c|c|c|c|c|c|c|c|c|c|c|c|}
\hline & $1^{*}$ & $2^{*}$ & $3^{*}$ & $4^{*}$ & $5^{*}$ & $6^{*}$ & $7^{*}$ & $8^{*}$ & $9^{*}$ & $10^{*}$ & $11^{\dagger}$ & $12^{\dagger}$ \\
\hline Cervical Vessel - Right & $\checkmark$ & $\checkmark$ & $\checkmark$ & $\checkmark$ & - & - & $\checkmark$ & $\checkmark$ & $\checkmark$ & $\checkmark$ & $\checkmark$ & $\checkmark$ \\
\hline Cervical Vessel - Left & - & $\checkmark$ & $\checkmark$ & $\checkmark$ & - & $\checkmark$ & - & - & $\checkmark$ & $\checkmark$ & $\checkmark$ & $\checkmark$ \\
\hline Thoracic Duct & $\checkmark$ & $\checkmark$ & $\checkmark$ & $\checkmark$ & $\checkmark$ & $\checkmark$ & $\checkmark$ & $\checkmark$ & $\checkmark$ & $\checkmark$ & - & $\checkmark$ \\
\hline Pre-scapular Vessel & - & - & - & - & - & - & - & - & $\checkmark$ & $\checkmark$ & - & - \\
\hline Jugular Vein & $\checkmark$ & $\checkmark$ & $\checkmark$ & $\checkmark$ & $\checkmark$ & $\checkmark$ & $\checkmark$ & $\checkmark$ & $\checkmark$ & $\checkmark$ & $\checkmark$ & $\checkmark$ \\
\hline Eye Tissue & $\checkmark$ & $\checkmark$ & $\checkmark$ & $\checkmark$ & $\checkmark$ & $\checkmark$ & $\checkmark$ & $\checkmark$ & $\checkmark$ & $\checkmark$ & $\checkmark$ & $\checkmark$ \\
\hline Lymph Node & - & - & - & - & - & - & $\checkmark$ & $\checkmark$ & $\checkmark$ & $\checkmark$ & $\checkmark$ & $\checkmark$ \\
\hline
\end{tabular}

* denotes intracameral injection of I-125 BSA

${ }^{\dagger}$ denotes application of I-125 BSA on the conjunctival surface 


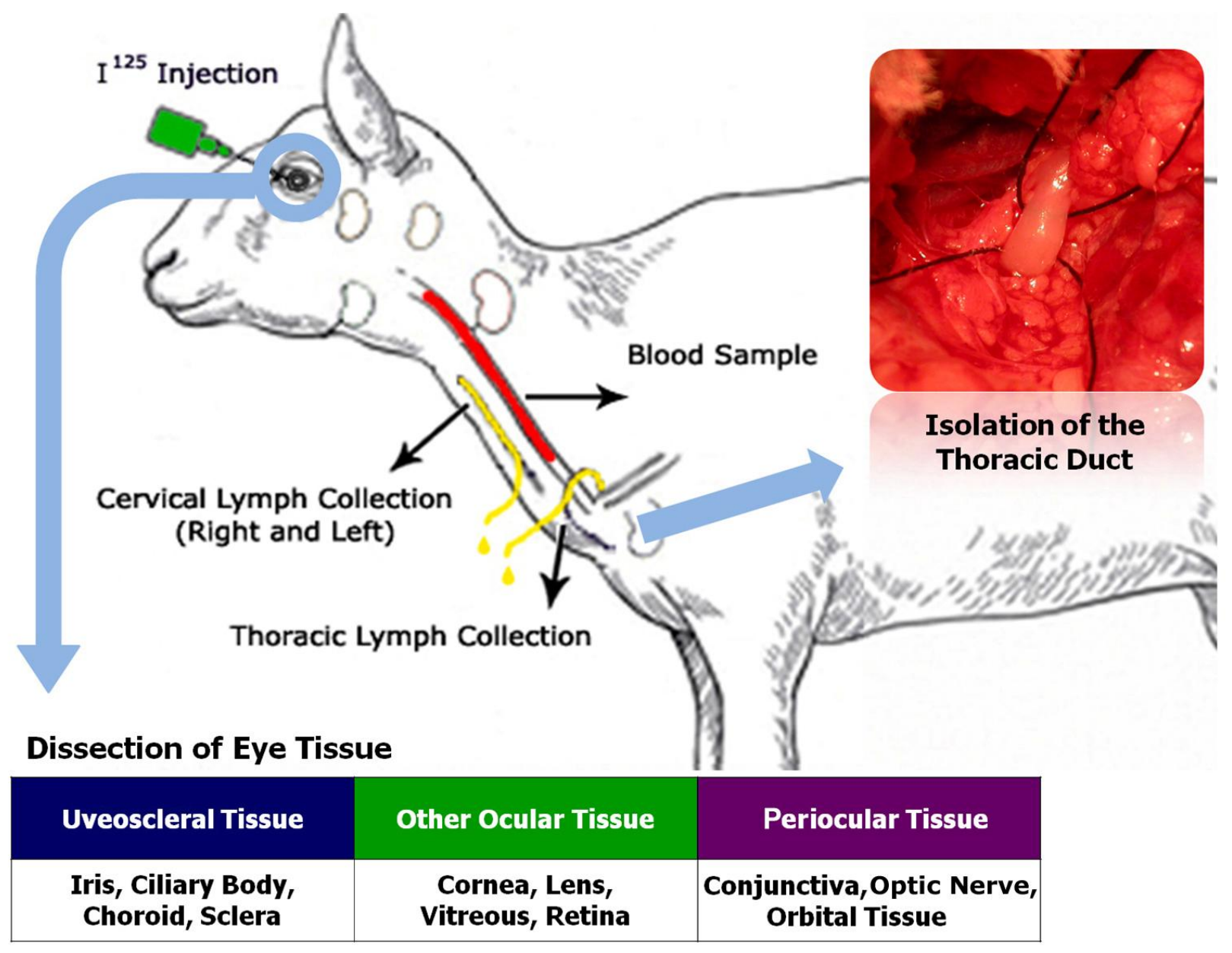

Figure 6. Schematic of the Experimental Methods The right and left cervical vessels, and the thoracic lymphatic duct was cannulated and lymph was collected in 15-minute intervals (a new sample collection started every 15 minutes). A catheter was inserted into the right jugular vein and blood samples were taken every 15 minutes. At the end of the experiment ( $3 \mathrm{hr}, \mathrm{n}=8 ; 5 \mathrm{hr}, \mathrm{n}=2$ ), the eye and the orbit was removed and dissected and grouped into specific groups as indicated in the figure. Radioactivity was measured in all the collected samples using a gamma counter. 


\subsection{IOP measurements}

With animals in the sternal recumbent position, IOP was measured with a tonometer (TonoPen XL, Colonial Medical Supply, Franconia, NH) before intracameral injection and 3 hours after injection - at the end of the experiment. Average IOP values were determined from four measurements (Passaglia et al., 2004). Paired t-test was performed to compare IOP before injection with IOP at the end of the experiment.

\subsection{Collection of ${ }^{125} \mathrm{I}-\mathrm{BSA}$ in lymph and plasma samples}

With lymphatic and intravenous (IV) catheters in place, sheep were placed in a sternal recumbent position - with their head on a head stand and chin resting on the bar. The anterior chamber of each eye was then injected with $25 \mu \mathrm{L}{ }^{125}$ I-labelled bovine serum albumin (BSA) (13.95 $\mu \mathrm{g}$ in $25 \mu \mathrm{L}$ saline) (Perkin-Elmer, Massachusetts, United States), using a $250 \mu \mathrm{L}$ Hamilton syringe (Hamilton Company, Reno, NV) and a $30^{1 / 2}$ gauge BD needle (Becton Dickinson, Oakville, Ontario, Canada). When the injection was complete, the needle was removed and a cotton swab gently held at the site of injection for 2 to 3 minutes.

Lymph from cervical vessels and the thoracic duct was collected continuously at 15minute intervals for $3(n=8)$ and $5(n=2)$ hours, respectively. For cases where lymph was collected from both right and left cervical lymph vessels (ID numbers 2, 3, 4, 9, and 10), measurements of the two samples were pooled, since there was no significant difference in radioactivity in right and left cervical lymphatics. In some cases, only one of the cervical vessels could be accessed for lymph collection - due to technical problems (ID number 5, 7 and 8), clot formation in the collecting tube (ID number 1 and 6) or the small size of the cervical lymphatics (ID number 5 and 7). Two additional animals were used to determine protein concentration in 
prescapular lymph.

To monitor plasma tracer levels, serial blood samples were taken every 15 minutes for 3 $(\mathrm{n}=8)$ and 5 hours $(\mathrm{n}=2)$. At each time point, two consecutive $3 \mathrm{~mL}$ samples were drawn. The first sample was put back in the jugular vein, followed by $3 \mathrm{~mL}$ of heparin/4\% dextrose saline (Hospira, Montreal, QC, Canada) to prevent blood clot formation in the tube. The second blood sample was placed in a plastic test tube with heparin $(15 \mathrm{U} / \mathrm{mL})$, centrifuged at $2400 \mathrm{rpm}$ for 15 minutes at room temperature, yielding an upper plasma layer, lower red blood cell layer and a thin white blood cell interface. One $\mathrm{mL}$ of upper plasma layer was pipetted into a separate tube for radioactivity measurement.

\subsection{Post-mortem harvesting of ocular and periocular tissues}

Three (ID numbers1-8) and 5 hours (ID numbers 9 and 10) after intracameral tracer injection, sheep were euthanized by IV injection of sodium pentothal (Euthanyl, Bimeda-MTC Animal Health Inc., Cambridge, ON, Canada), aqueous humor collected using a 30-gauge needle, and right and left periocular orbital tissue with eyes exenterated. Eyes were then dissected into uvea (ie, iris, ciliary body and choroid) and sclera - as well as other ocular (cornea, retina, vitreous body) and periocular (conjunctiva, orbital tissue and optic nerve) tissues, and radioactivity measured. Uveoscleral drainage was calculated as the quantity of tracer retained in the uvea and sclera during the specified time interval (Toris, 2008). 


\section{$2.6 \quad{ }^{125}$ I-BSA measurements}

Radioactivity in plasma, lymph, ocular tissue, and lymph node samples was measured using a gamma counter (Compu-gamma, LKB Wallac, Turku, Finland), with appropriate window settings and background subtraction. To ensure that most of the measured radioactivity in any sample was protein-bound, a second set of aliquots was assayed after precipitation with $10 \%$ trichloroacetic acid; free or non-protein-bound ${ }^{125} \mathrm{I}$ amounted to $<15 \%$ of the total radioactivity.

\subsubsection{Lymph ${ }^{125}$ I-BSA measurements and correction for re-filtration (Figure 7)}

When ${ }^{125}$ I-BSA is injected into the anterior chamber, a portion of this will be carried to the systemic circulation, and this will re-circulate to the tissues, which will return to lymph. Thus the tracer recovered in lymph would have not originated solely from the anterior chamber. To assess the extent of blood to lymph transfer of radioactivity, the pre-scapular efferent lymph sample was used as a control. Because the pre-scapular lymphatics do not drain fluid and protein from the head and neck region, all of the radioactivity observed in this sample would have originated from re-circulation of tracer that had initially entered the plasma. The radioactive tracer levels found in the pre-scapular lymph can be used to measure the degree of overestimation of tracer recovery values in the cervical vessel lymph determined from the initial experiments (Figure 7). In these sheep, the pre-scapular lymphatic vessel and the right and left cervical lymph vessels were cannulated. The recovered radioactivity from the pre-scapular lymph was used as the re-filtration value to make corrections to the recovered radioactivity from the cervical and thoracic lymph values. We devised a mathematical method based on protein 


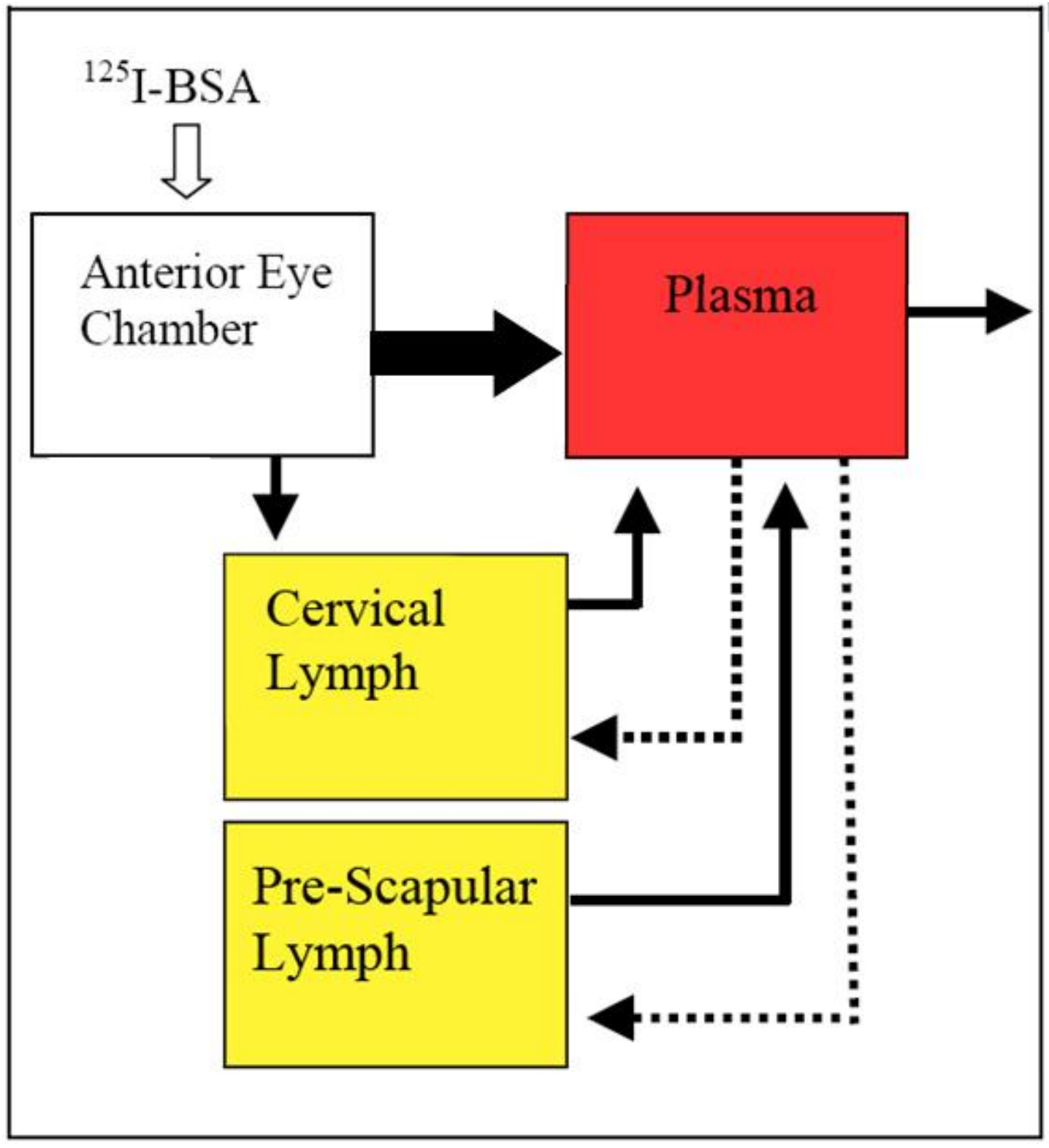

Figure 7. Engineer's model of the aqueous humor including the prescapular lymph The figure shows the two proposed drainage systems, the systemic circulation and the lymphatic circulation. The pre-scapular lymph is used to determine the amount of re-filtration from blood to lymph (Section 2.6.1) Because the pre-scapular lymphatics do not drain fluid and protein from the head and neck region, all of the radioactivity observed in this sample would have originated from re-circulation of tracer that had initially entered the plasma (dotted line). The radioactive tracer levels found in the pre-scapular lymph can be used to determine the degree of overestimation in the lymph samples. 
concentrations in lymph, since the degree of macromolecule restriction of the microvasculature in the drainage basins of the lymphatics vary depending on their anatomical locations. The degree of macromolecule restriction of the microvasculature wall, indicated by the osmotic reflection coefficient, differs between the different tissue compartments. For example, this value is relatively large for proteins in the liver. As follows, the concentration of proteins found in lymphatic vessels of the liver is high compared to other body compartments (Figure 8). In order to be justified in using the pre-scapular lymph as a control value to correct for the level of blood to lymph transfer of radioactivity, protein levels of the pre-scapular lymph and cervical lymph were compared. 
(a)

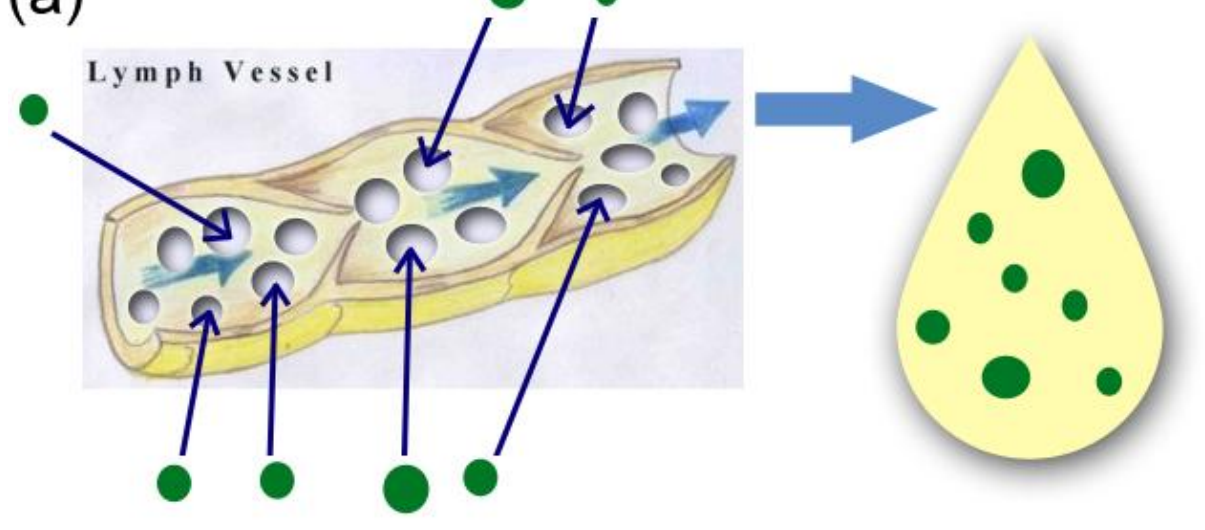

(b)

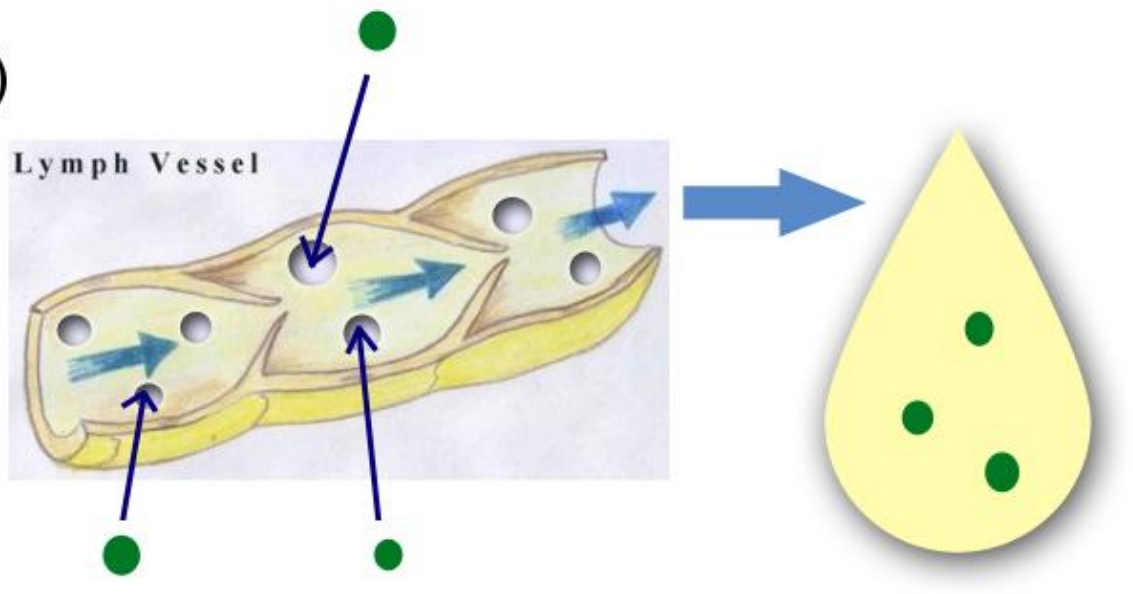

Figure 8. The differing degree of macromolecule restriction in lymphatic vessels located throughout the body. The degree of macromolecule restriction of the microvasculature wall, indicated by the osmotic reflection coefficient, differs between the different tissue compartments. For example this value is relatively large for proteins in the liver (a) compared to other parts of the body such as in the forelimb (b). As follows, the concentration of proteins found in lymphatic vessels of the liver is high compared to other body compartments. (Modified from http://www.fgf.uk.com/content/lymphaticsystem) 
First, prior to ${ }^{125}$ I-BSA injection, total protein concentration in lymph from the prescapular vessel was determined $(25.71 \pm 3.74 \mu \mathrm{g} / \mu \mathrm{L}, \mathrm{n}=6)$, using a bicinchoninic acid (BCA) protein assay kit (Thermo Scientific, IL). Following intracameral injection of ${ }^{125} \mathrm{I}-\mathrm{BSA}$, average tracer concentration in prescapular lymph was calculated (ID numbers 9 and 10). To estimate the amount of filtered tracer in prescapular lymph as a function of protein concentration, total radioactivity measured in lymph (Pre-scapular) was divided by the product of the lymph volume collected and the average protein concentration. To derive this value, we used the data from the first 90 minutes post-injection. For lymph from cervical vessels, the total mass of protein over 3 hours was calculated as the product of volume and average protein concentration - or $20.69 \pm$ $3.07 \mu \mathrm{g} / \mu \mathrm{L}(\mathrm{n}=8)$ as determined by the BCA assay. Radioactivity in cervical lymph due to refiltration from plasma was determined as the product of the prescapular $\mathrm{cpm} / \mathrm{mg}$ value and the mass of tracer. This value was then subtracted from the actual measured radioactivity in cervical lymph (volume $\mathrm{X}$ radioactivity/ml) to give an estimate of tracer entry into the cervical vessels directly from the eye.

For lymph from thoracic duct, the total mass of protein over 3 hours was calculated as the product of volume and average protein concentration - or $40.17 \pm 7.22 \mu \mathrm{g} / \mu \mathrm{L} ;(\mathrm{n}=8)$. Radioactivity in thoracic duct lymph due to re-filtration from plasma was estimated as the product of the prescapular $\mathrm{cpm} / \mathrm{mg}$ value and the mass of tracer as calculated above. This value was then subtracted from the actual measured radioactivity in thoracic duct lymph (volume $\mathrm{X}$ radioactivity $/ \mathrm{ml}$ ) to give an estimate of tracer entry into thoracic duct directly from the eye.

Based on these parameters, radioactivity per mg protein was estimated for prescapular lymph and the mass of filtered tracer was subtracted from the measurement of lymph from vessels of interest. Figure 9 shows an example of the calculations explained above using numerical values. 
Pre-scapular Lymph:

Total tracer collected:

Total volume collected:

Protein concentration:

Total amount of protein (BSA):

Concentration of re-filtered tracer:
$3739 \mathrm{cpm}$

$3.2444 \mathrm{~mL}$

$25.712 \mu \mathrm{g} / \mu \mathrm{L}$

$3.2444 \mathrm{~mL} * 25.712 \mu \mathrm{g} / \mu \mathrm{L}$

$3739 \mathrm{cpm} /(3.2444 \mathrm{~mL} * 25.712 \mu \mathrm{g} / \mu \mathrm{L})$

$$
=3.62 \mathrm{cpm} / \mathrm{mg}
$$

\section{Thoracic Duct Lymph:}

Total volume collected:

$339.36 \mathrm{~mL}$

Protein concentration:

$40.172 \mu \mathrm{g} / \mu \mathrm{L}$

Total amount of protein (BSA):

$339.36 \mathrm{~mL} * 40.172 \mu \mathrm{g} / \mu \mathrm{L}$

Amount of tracer from re-filtration: $\quad 3.62 \mathbf{~ c p m} / \mathbf{m g}$ * $(339.36 \mathrm{~mL} * 40.172 \mu \mathrm{g} / \mu \mathrm{L})$

$$
=594690.91 \mathrm{cpm}
$$

Experimentally determined amount of tracer recovery

$$
805092 \mathrm{cpm}
$$

Corrected amount of tracer recovery:

Figure 9. Example of the calculations for re-filtration correction using numerical values (Section 2.6.1) 


\subsubsection{Plasma ${ }^{125}$ I-BSA measurements and correction for re-filtration (Figure 7)}

The total quantity of tracer in plasma was used to estimate trabecular drainage, which is known to drain to the general circulation (Gabelt and Kaufman 1989). Radioactivity for each plasma sample collected every 15 minute was tabulated and the data corrected for re-filtration of tracer from the plasma to various tissue components using the average rate of albumin elimination from plasma of 6.5\% per hour (Boulton et al., 1997; Boulton, Armstrong et al., 1998; Boulton, Flessner et al., 1998; Boulanger et al., 1999). Thus, 6.5\% of the plasma radioactivity was added back to the radioactivity recovered in plasma for each hour of the experiment. Plots of

${ }^{125}$ I-BSA concentration of the ten sheep over time showed that measurements increased rapidly before starting to plateau about 30 minutes after injection. The ${ }^{125} \mathrm{I}-\mathrm{BSA}$ concentration at the plateau for each sheep was estimated by fitting a line to the data and determining the value 180 minutes after tracer injection. To estimate the plateau value, each measurement after 15 minutes post-injection was converted to natural log. Analysis of variance was performed using PROC GLM in SAS (SAS Institute, NC), and a model (measurement $=$ subject + (subject * (time 180)). By using the "no intercept" option in PROC GLM and subtracting 180 from time, the parameters estimated the $\log$ of concentration at time $=180$ for each subject; $95 \%$ confidence limits (95\% CL) around plateau values were calculated, and plateau values back-converted to the original scale.

The plasma volume $(\mathrm{ml})$ calculation, the product of 21.77 and the animal's weight $(\mathrm{kg})+$ 649.68, is based on previously published plasma volumes derived from 41 sheep against their weights (Boulton et al., 1997; Boulton, Armstrong et al., 1998; Boulton, Flessner et al., 1998; Boulanger et al., 1999). The total quantity of tracer in plasma was calculated by multiplying the 
plateau value of plasma concentration at 180 minutes after injection with plasma volume, as calculated above.

Lymphatic, trabecular and uveoscleral drainage were calculated as percentage of tracer in lymph, plasma and uveoscleral tissue of total drainage, respectively. Percentage of tracer in other ocular tissue and percentage of tracer in periocular tissues of total drainage were also calculated. Total drainage was considered as the sum of tracer recovered from lymph, plasma, uveoscleral tissues, and other ocular and periocular tissues.

To study the time course of lymphatic drainage and plasma (trabecular) drainage, we calculated radioactive tracer levels over 180 minutes following intracameral injection of ${ }^{125} \mathrm{I}-$ BSA. Lymphatic drainage at various time points was estimated as percentage of the total amount radioactivity (cpm) in lymph -cervical lymphatics and thoracic duct- over the 180 minutes. Plasma (trabecular) drainage at various time points was estimated as percentage of the total amount radioactivity (cpm) in plasma over the 180 minutes. 


\subsection{Impact of tracer drainage from conjunctiva-lacrimal ductal pathway}

The punctum lacrimales lead to the lacrimal sac and the nasolacrimal duct, and then into the highly vascular nasal mucosa. This is the primary pathway for the systemic absorption of topical eye medications. Because some leakage occurred during intracameral injections, control experiments were conducted to verify that this route was not contributing to tracer recovery in the plasma or lymph. Thus, it was important to determine whether tracer leaked during or after intracameral injection and drained via the conjunctiva-lacrimal ductal pathway into the plasma and lymph.

To test this, ${ }^{125}$ I-BSA was applied topically to the conjunctiva in two sheep (the same mass as injected into aqueous humor), and then lymph and blood samples were collected and measured as described above. 


\section{CHAPTER 3:}

\section{IS THERE DRAINAGE OF AQUEOUS HUMOR INTO THE LYMPHTIC SYSTEM: RESULTS}


Chapter 3: Is there drainage of aqueous humor into the lymphatic system: Results

3.1 Intraocular pressure and Aqueous Humor volume ............................ 49

3.2 Quantitative studies of the recovery of ${ }^{125} \mathrm{I}-\mathrm{BSA}$ in plasma

(Conventional outflow) ............................................ 50

3.3 Quantitative studies of the recovery of ${ }^{125}$ I-BSA in the uveoscleral eye tissue

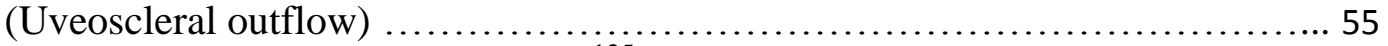

3.4 Quantitative studies of the recovery of ${ }^{125} \mathrm{I}-\mathrm{BSA}$ in lymph

('Uveo-lymphatic' outflow) ........................................ 56

3.5 Quantitative studies of the recovery of ${ }^{125}$ I-BSA in lymph nodes .................. 58

3.6 Impact of tracer drainage from conjunctiva-lacrimal ductal pathway . .............. 60

3.7 Adjustments of tracer recoveries in lymph and plasma due to re-filtration ..........62 


\subsection{Intraocular pressure and Aqueous Humor volume}

Average IOP values before and 3 hours after injection were not significantly different (right eye, $10.75 \pm 4.19 \mathrm{mmHg}$ vs. $11.00 \pm 4.83 \mathrm{mmHg}$ ( $p>0.05$ ); left eye: $10.50 \pm 3.70 \mathrm{mmHg}$ vs. $10.00 \pm 3.46 \mathrm{mmHg}(p>0.05)$; mean $\pm \mathrm{SD})(\mathrm{n}=4$, ID numbers $3,6,7$ and 8$)$. The IOP values obtained are consistent with the values obtained in healthy sheep by other groups, which were found to be $10.6 \pm 1.4 \mathrm{mmHg}$ (Gerometta et al., 2009; 2010).

When the eye was enucleated at the end of the experiment, the aqueous humor volume was withdrawn using a micro-syringe. The aqueous humor volume was determined to be $527 \pm$ $148 \mu \mathrm{L}$. 


\subsection{Quantitative studies of the recovery of ${ }^{125} \mathrm{I}-\mathrm{BSA}$ in plasma (Conventional outflow)}

Following injection of the tracer into both eyes, we observed a rapid increase in radioactivity in blood. Generally, blood tracer levels increased steadily after injection until 60-75 minutes, at which point a plateau in the radioactivity versus time plot was observed. This pattern of recovery over time is illustrated in Figure 10 (one representative experiment). The tracer recovery levels over time can also be expressed as a percentage of the total tracer recovery in each compartment (blood and lymph) to demonstrate the pattern of tracer recovery (Figure 11).

The relative distribution of tracer recovery in the individual components was

demonstrated by creating a 'balance sheet' of tracer using the amount of ${ }^{125}$ I-BSA in the eye, blood and lymph samples added together to give 100\%. At the 3 hour end point, the relative level of tracer recovered in plasma was $64.7 \%$. This can be thought of as having been drained via the conventional outflow pathway. Figure 12 shows the recovery of total tracer over time in both the lymph and plasma compartments. 


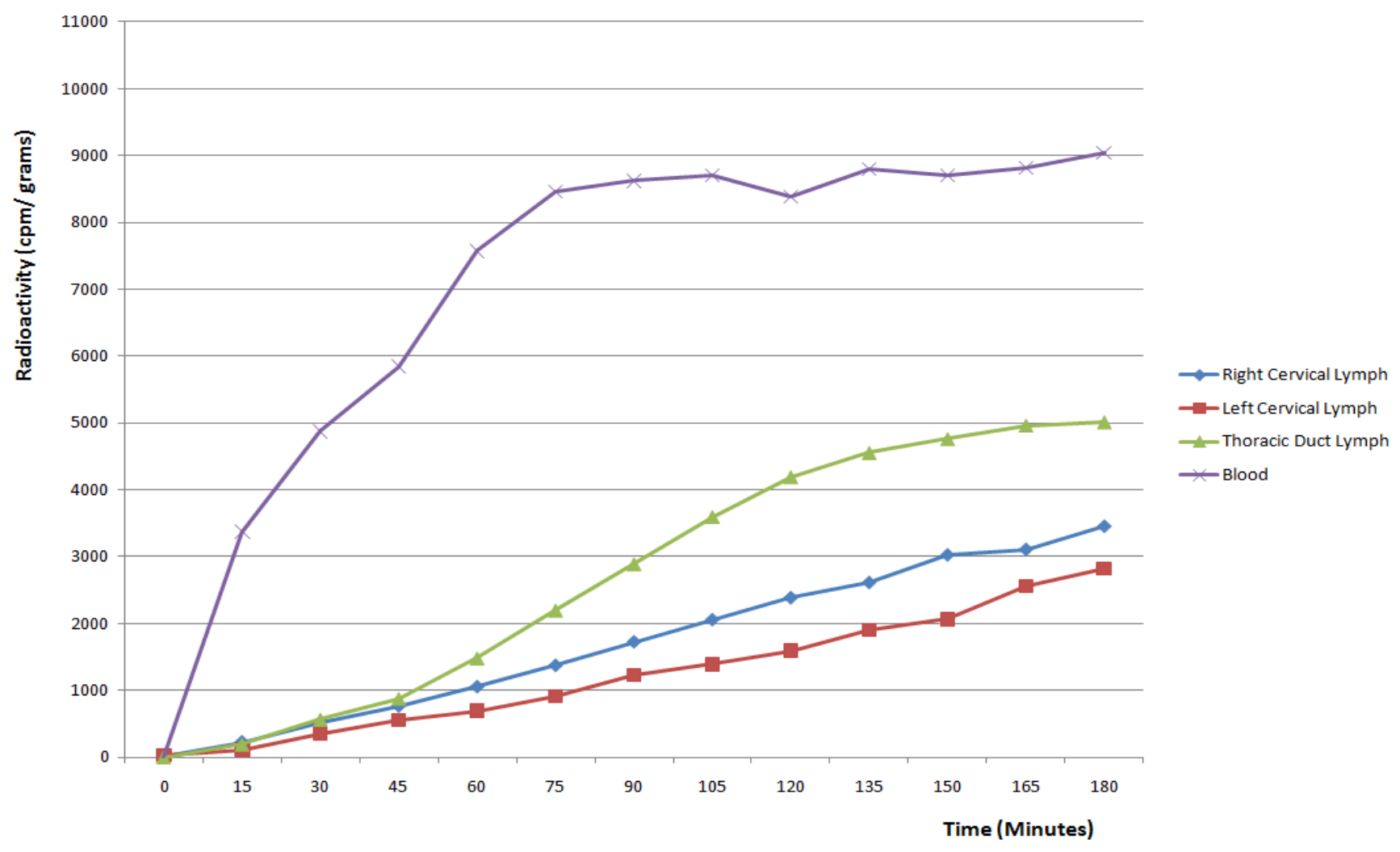

Figure 10. Representative example of the change in the concentration of radioactivity over 3 hours post $I^{125}$-BSA Injection into the anterior chamber The top line shows the change in tracer concentration over time in plasma, with the 3 lower line in lymph. The concentration increases rapidly in plasma within the first 75 minutes and then plateaus. On the other hand, the concentration increases slowly in the lymph compartments and continues to rise at 3 hours. (ID\#: 4) 

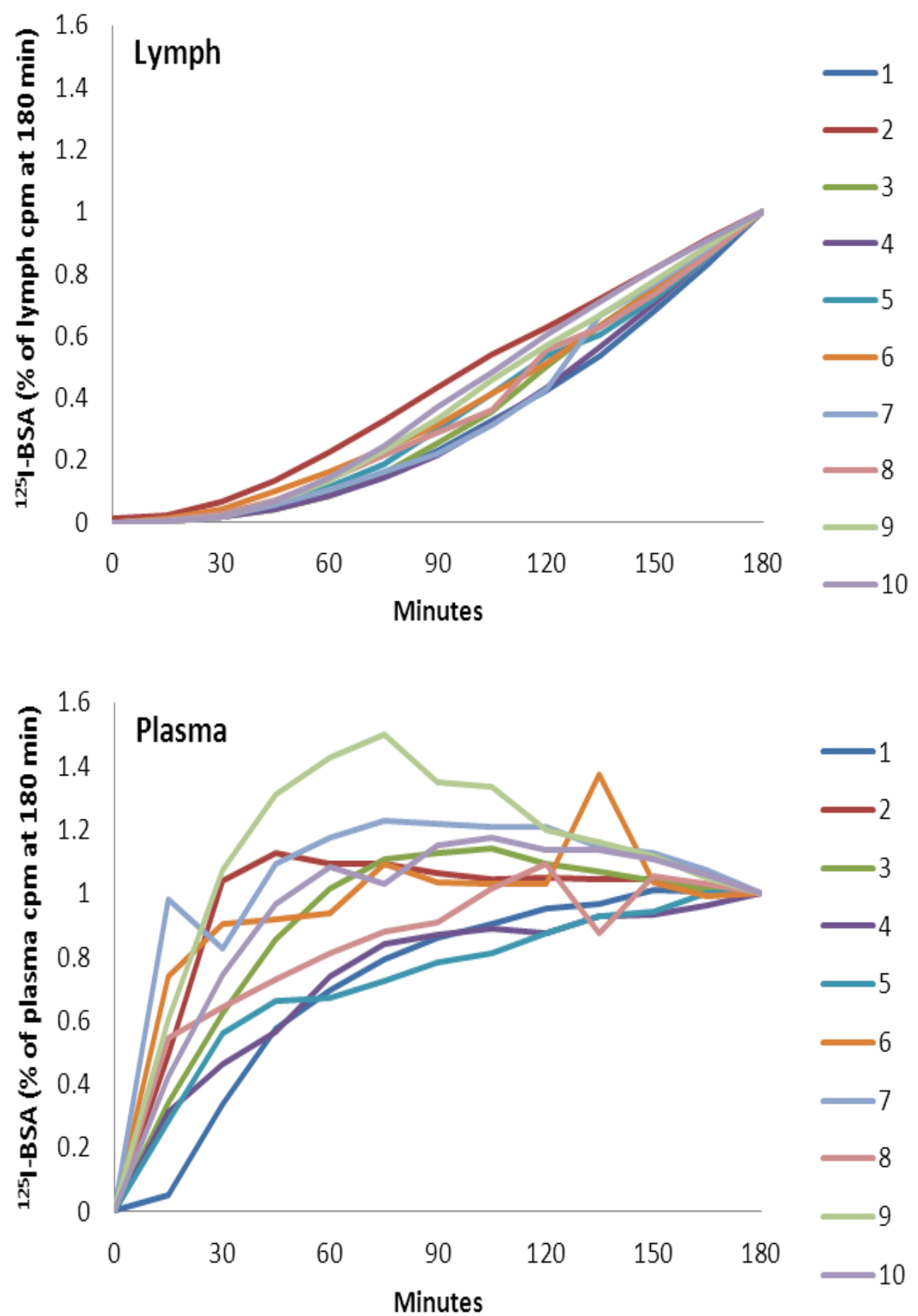
Figure 11. Time course recovery of tracer recovery expressed as a percentage of total recovery in Lymph and Plasma. Time course of lymphatic and plasma (trabecular) drainage assessed by monitoring radioactive tracer levels over 180 minutes following intracameral injection of ${ }^{125}$ I-BSA. Lymphatic drainage at various time points was estimated as percentage of the total amount radioactivity (cpm) in lymph -cervical lymphatics and thoracic duct- over the 180 minutes. Plasma (trabecular) drainage at various time points was estimated as percentage of the total amount radioactivity $(\mathrm{cpm})$ in plasma sample from the right jugular vein- over the 180 minutes. While lymphatic drainage (A) increased steadily over the time period, trabecular drainage (B) increased rapidly - plateauing at 30 minutes. The numbers on the right correspond to animal ID numbers. 


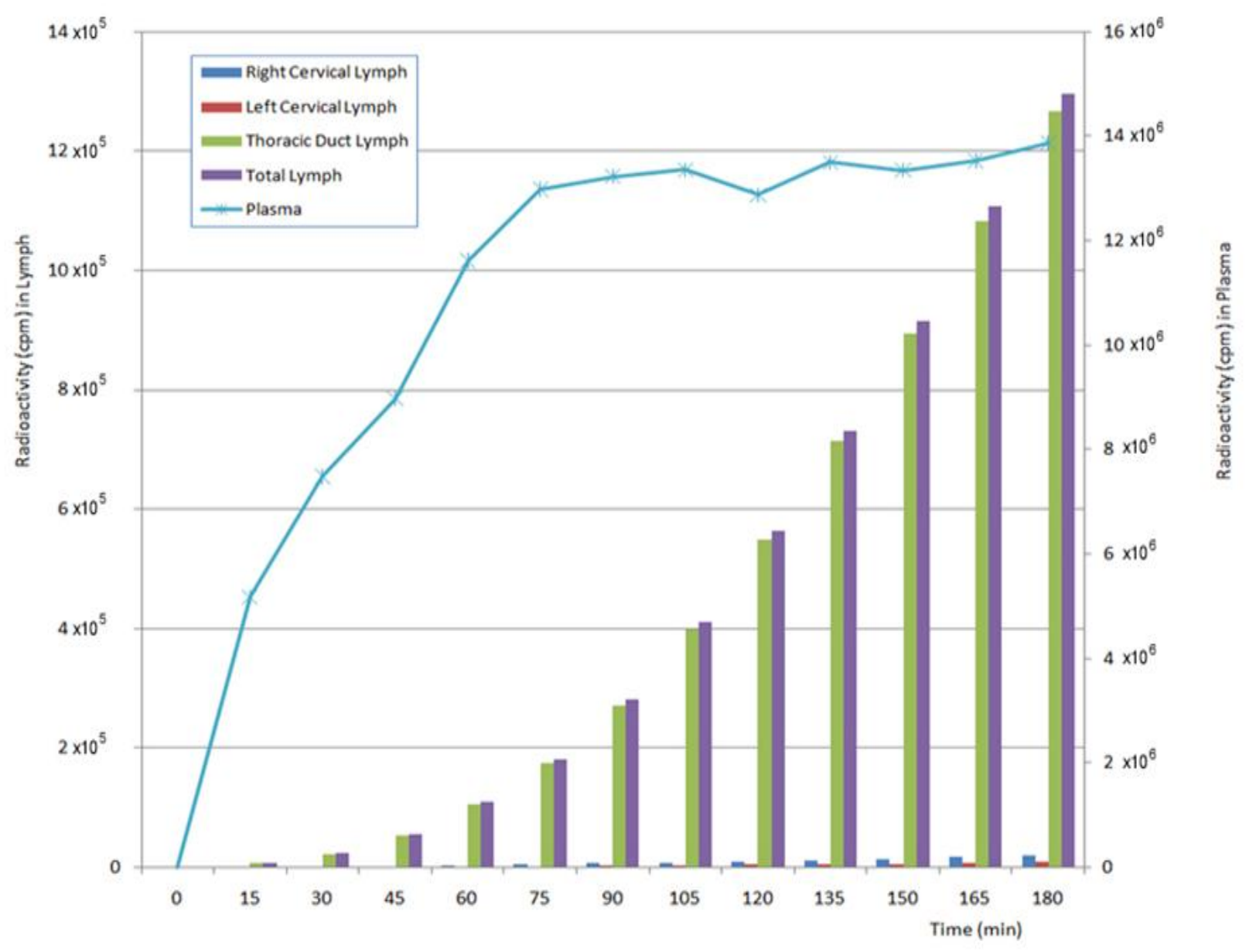

Figure 12. Representative example of the time course recovery of radioactivity $(n=1)$ The figure shows the total tracer recovery over time in plasma and lymph. The line shows tracer recovery in plasma. The total amount of tracer recovered stays at a constant level after the 75-minute time point. The total amount of tracer recovery in lymph increases at a much slower rate compared to plasma (note: different scale bars for plasma and lymph). As seen earlier with the concentration graph, the level of tracer recovery continues to increase past the 3-hour time point in lymph. (ID\#: 4) 


\subsection{Quantitative studies of the recovery of ${ }^{125}$ I-BSA in the uveoscleral eye tissue (Uveoscleral outflow)}

The relative distribution of tracer recovery in the individual components was

demonstrated by creating a 'balance sheet' of tracer using the amount of ${ }^{125}$ I-BSA in the eye, blood and lymph samples added together to give $100 \%$. At the 3-hour end point, there was a total of $26.7 \%$ found in enucleated eyes (right and left combined), and when the eye tissue was dissected into each of its compartments, $67.8 \%$ of this value (18.1\% of the total) was found in the uveoscleral tissue (iris, ciliary body, choroid, sclera). The amount of tracer found in the uveoscleral tissue can be thought of as having been drained via the uveoscleral outflow pathway, which is how uveoscleral outflow is commonly measured. 


\subsection{Quantitative studies of the recovery of ${ }^{125}$ I-BSA in lymph ('Uveo-lymphatic' outflow)}

The current study adds a new dimension to measuring aqueous humor outflow, by also measuring tracer recovery in lymph. Based on previous experiments by Yucel et al (2009), the tracer found in lymph can be thought of as being drained via the lymphatic vessels in the ciliary body. It can be thought as being continuous to the uveoscleral outflow pathway, and thereby termed the 'uveo-lymphatic outflow'.

Both the cervical lymphatics and the thoracic duct flowed continuously for the duration of the 3- hour, and 5- hour experiments, except in 2 sheep where a clot formed inside the collecting tube of the cervical lymphatic vessel stopping lymph flow. In 4 animals, we were only able to cannulated one of the cervical ducts due to technical issues. In the cases where both the right and left cervical lymph vessels were cannulated successfully $(n=5)$, we observed that there were no significant differences between the radioactivity measured in the two vessels. In most animals, other cervical ducts were identified. However these were generally too small for cannulation. Based on previous experience from Johnston's group, these vessels either empty into the venous system independently, or occasionally join with the thoracic duct at a point upstream of the point of cannulation.

The average flow rates were $3.94 \mathrm{~mL} / \mathrm{hr}, 3.56 \mathrm{~mL} / \mathrm{hr}$, and $126 \mathrm{~mL} / \mathrm{hr}$ for the right cervical lymph, left cervical lymph and the thoracic duct, respectively. In the animals where the prescapular vessels were cannulated, the flow rate was shown to be $1.31 \pm 0.12 \mathrm{~mL} / \mathrm{hr}$.

In contrast to the rapid increase in tracer levels seen in blood, the level of tracer in the

cervical and thoracic duct lymph increased slowly and the concentrations of ${ }^{125}$ I-BSA in these vessels were considerably lower than those recorded in blood. An example from one representative experiment is illustrated in Figure 8. The tracer recovery levels over time can also 
be expressed as a percentage of the total tracer recovery in each compartment (blood and lymph) to demonstrate the pattern of tracer recovery (Figure 11).

The relative distribution of tracer recovery in the individual components was demonstrated by creating a 'balance sheet' of tracer using the amount of ${ }^{125}$ I-BSA in the eye, blood and lymph samples added together to give $100 \%$. At the 3 -hour end point, the relative level of tracer recovered in lymph was $0.23 \%$ for the cervical lymph, $8.35 \%$ for the thoracic duct lymph. Figure 12 shows the recovery of total tracer over time in both the lymph and plasma compartments

It is interesting to note that the level of tracer recovery in lymph continues to increase at the 3 hour point, which may indicate that the portion of radioactivity recovered in the lymph compartments will be greater if the tracer levels were monitored for a longer period of time. The tracer levels were still high in the uveoscleral eye tissues (iris, ciliary body, choroid, sclera) at the end of 3 hours. It is possible that over time, more of the injected tracer would leave the ciliary body and enter the lymphatic system. The tracer recovery distribution for the 5-hour experiments $(n=2)$ is seen in figure 17 (corrected for re-filtration, compare to figure 16 at 3 hours). 


\subsection{Quantitative studies of the recovery of ${ }^{125}$ I-BSA in lymph nodes}

Figure 13 illustrates the $\mathrm{cpm} / \mathrm{gm}$ of radioactivity in the excised lymph nodes. As predicted, the cervical nodes had significantly greater radioactivity than the others $(\mathrm{p}<0.05)$ as these are positioned on the lymphatic outflow pathway that received aqueous humor. We can get an idea of the amount of radioactivity present in the vasculature of the nodes from the counts in the nodes not located on the aqueous humor outflow pathway. In any event, even the tracer recoveries in the cervical nodes $(n=4)$ were very low $(0.025 \pm 0.012 \%$ of total recovery $)$ and were not included in the analysis of tracer distribution. 


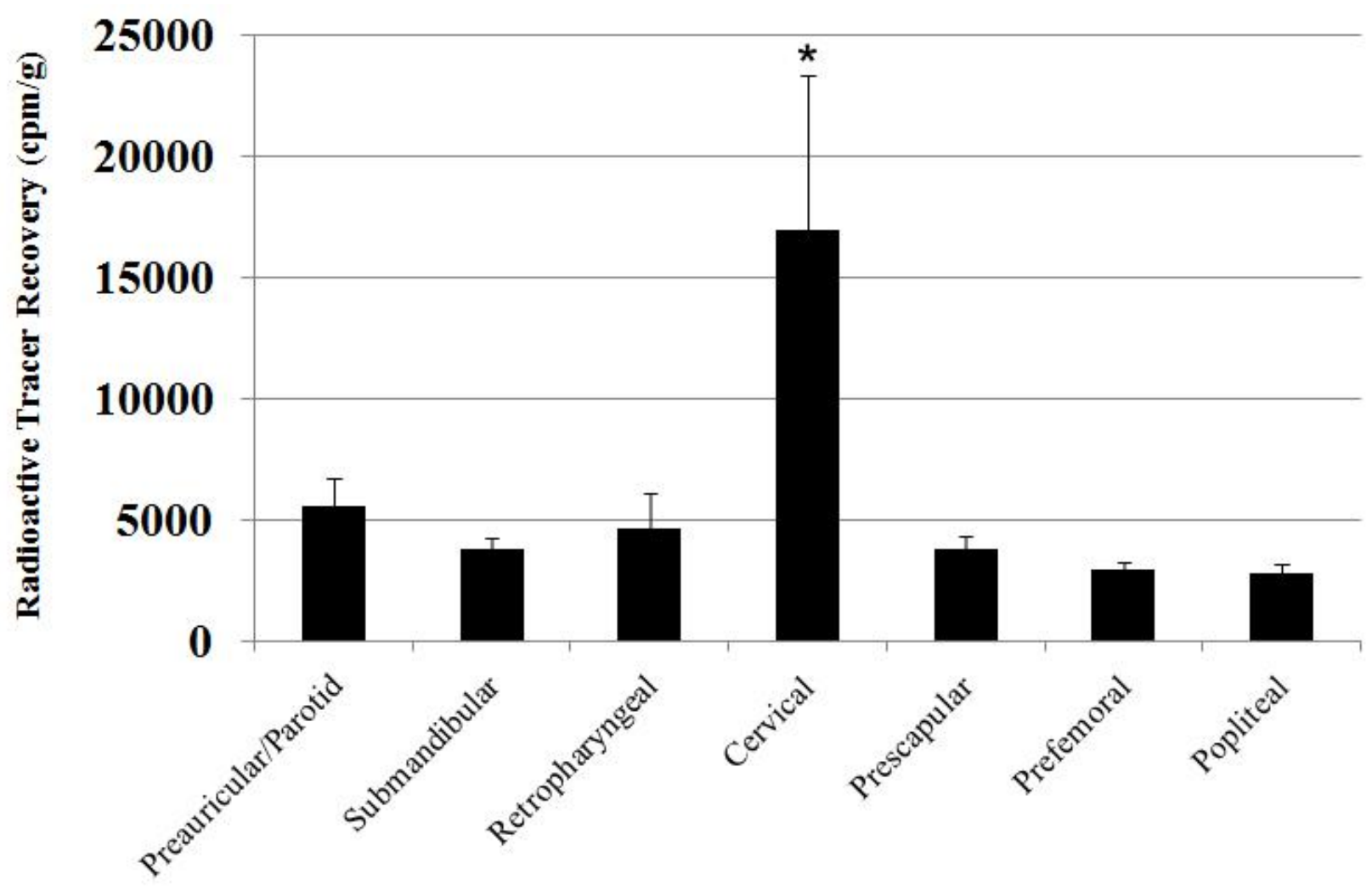

Figure 13. Radioactive tracer recovery in various lymph nodes $(n=5)$. Data from the right and left nodes were pooled in generating the graph. The level of tracer recovery was the highest in the cervical lymph nodes, and lowest in the pre-femoral and popliteal lymph nodes. There were significant differences in radioactivity counts in the preauricular/parotid, submandibular, retropharyngeal, prescapular, prefemoral, and popliteal lymph nodes compared to the cervical lymph nodes site. One-way repeated ANOVA measures followed by single degree of freedom contrasts were used for each comparison $(\mathrm{P}<0.05)$ 


\subsection{Impact of tracer drainage from conjunctiva-lacrimal ductal pathway}

We were concerned initially that any tracer leaking out of the eye would enter the nasolacrimal duct and gain access to the highly vascular nasal mucosa. However, over three hours following topical ${ }^{125} \mathrm{I}$-BSA application to the conjunctiva, $0 \%$ and $0.06 \%$ of total recovered tracer was detected in the lymph, and $8.70 \%$ and $3.82 \%$ in plasma. Based on these control experiments, we concluded that any tracer leakage onto the conjunctival surface during or after

intracameral injection did not contribute significantly to tracer accumulation in lymph and plasma (Figure 14). 


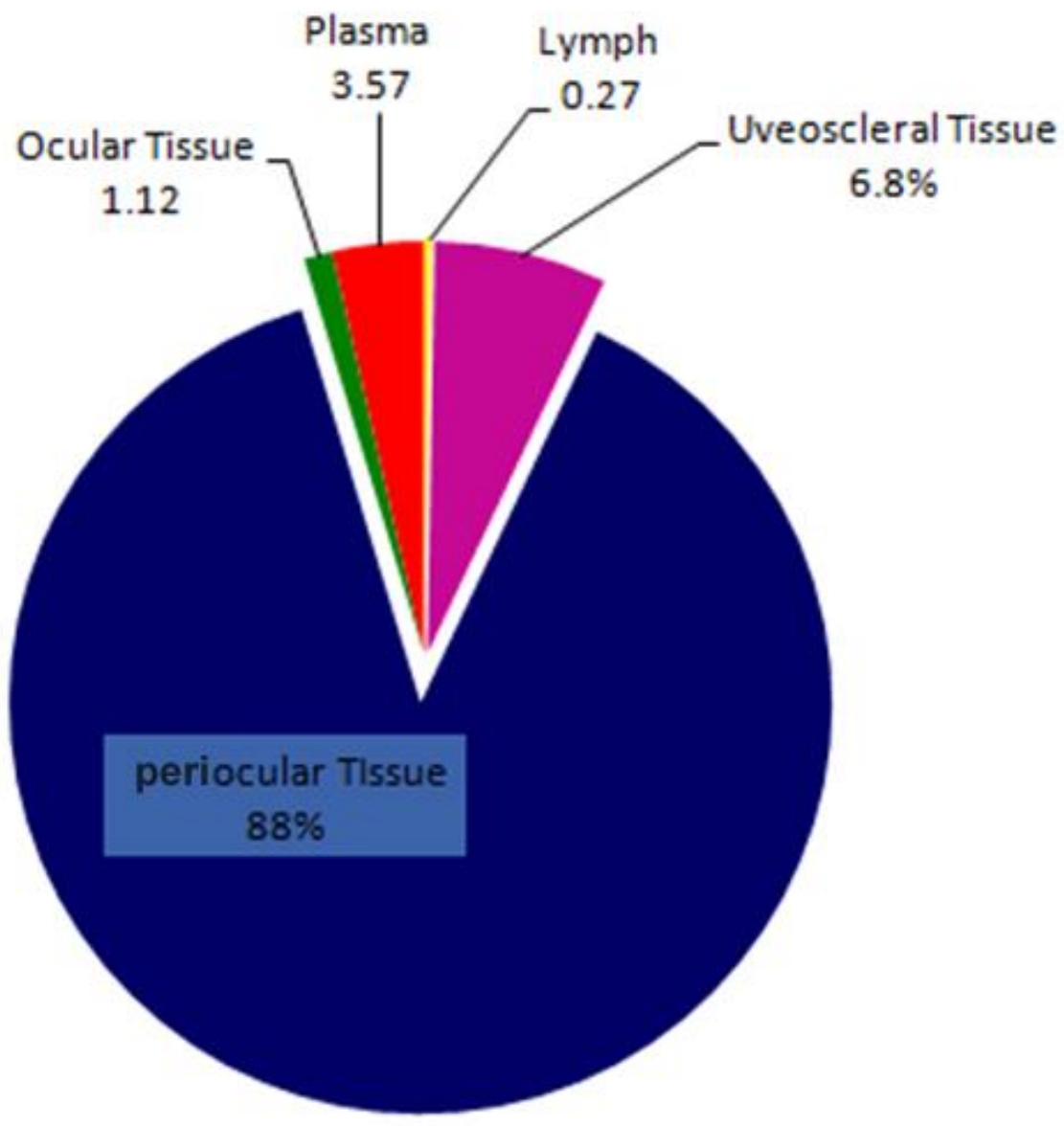

Figure 14. Distribution of Tracer Recovery in the Various Compartments with a Topical Application of Tracer (n=2, 3 hours) Minimal amount of tracer was found in the plasma and lymph compartment compared to the main experiments with intracameral injection of tracer (Compare to Figure 13). 


\subsection{Adjustments of tracer recoveries in lymph and plasma due to re-filtration}

To adjust tracer recoveries in lymph for ${ }^{125}$ I-BSA that likely entered the lymph samples from plasma rather than directly from the eye, we measured the albumin concentrations in each lymph compartment. These were $25.7 \pm 3.74 \mu \mathrm{g} / \mu \mathrm{L}$ for the pre-scapular lymph $(\mathrm{n}=6), 40.2 \pm$ $7.22 \mu \mathrm{g} / \mu \mathrm{L}$ for thoracic duct lymph (n=8), and $20.7 \pm 3.07 \mu \mathrm{g} / \mu \mathrm{L}$ for cervical lymph $(\mathrm{n}=8)$. As noted earlier, we assumed that the recovery of tracer in prescapular lymph was due entirely to refiltration of the tracer from the plasma and calculated the theoretical correction factor for cervical and thoracic duct lymph using the relative proportion of protein in each lymph compartment. As expressed as a percentage of the total tracer recovered (eye plus blood plus lymph), lymph recoveries adjusted for plasma-filtered tracer declined while those in the plasma increased. The cervical values decreased to $48 \%$ of the raw counts (from $0.24 \%$ to $0.11 \%$ ) and the thoracic duck lymph decreased to $23 \%$ of the raw counts $(8.35 \%$ to $1.91 \%)$. As noted earlier, using the rate of albumin elimination from plasma at $6.5 \% / \mathrm{hr}$, the plasma value increased to $108 \%(64.7 \%$ to $70.2 \%$ ) of its original measurements. Table 4 shows the corrected values for the distribution of tracer in each of the compartments assessed. The distribution of tracer recovery using the corrected values is shown in figure 16 using a pie graph. This can be compared to figure 15 , which shows the distribution of tracer recovery before the corrections are made. 
Table 4. Distribution of Radioactive Tracer in the Compartments Assessed (n=10)

\begin{tabular}{|c|c|c|c|c|c|c|c|c|}
\hline & \multicolumn{3}{|c|}{ Lymph: } & \multirow{2}{*}{$\begin{array}{c}\text { Uveoscleral Tissue: } \\
\text { Iris, Ciliary Body, } \\
\text { Choroid, Sclera }\end{array}$} & \multirow{2}{*}{$\begin{array}{c}\text { Other Ocular Tissue: } \\
\text { Cornea, Lens, } \\
\text { Vitreous, Retina } \\
\end{array}$} & \multirow{2}{*}{$\begin{array}{c}\text { Periocular Tissue: } \\
\text { Conjunctiva, Orbit, } \\
\text { Optic Nerve }\end{array}$} & \multirow[b]{2}{*}{ Plasma } \\
\hline & & Cervical & Thoracic & Total & & & & \\
\hline \multirow{11}{*}{$\begin{array}{c}3 \\
h s\end{array}$} & 1 & 0.02 & 0.50 & 0.52 & 16.3 & 3.19 & 3.27 & 76.7 \\
\hline & 2 & 0.17 & 2.02 & 2.19 & 18.2 & 12.1 & 5.76 & 61.8 \\
\hline & 3 & 0.08 & 1.42 & 1.50 & 11.1 & 1.84 & 1.93 & 83.7 \\
\hline & 4 & 0.06 & 1.28 & 1.34 & 16.9 & 2.06 & 2.44 & 77.3 \\
\hline & 5 & $N / A$ & 0.87 & 0.87 & 18.7 & 3.58 & 8.18 & 68.7 \\
\hline & 6 & 0.07 & 1.02 & 1.09 & 25.9 & 4.99 & 7.13 & 60.9 \\
\hline & 7 & 0.22 & 2.29 & 2.51 & 24.5 & 3.82 & 6.04 & 63.2 \\
\hline & 8 & 0.22 & 2.92 & 3.14 & 27.5 & 2.84 & 7.84 & 58.7 \\
\hline & $\begin{array}{c}\text { Lower } \\
C L\end{array}$ & 0.05 & 0.86 & 0.90 & 15.2 & 1.54 & 3.26 & 61.1 \\
\hline & Mean & 0.12 & 1.54 & 1.64 & 19.9 & 4.30 & 5.32 & 68.9 \\
\hline & $\begin{array}{c}\text { Upper } \\
C L \\
\end{array}$ & 0.20 & 2.22 & 2.39 & 24.6 & 7.07 & 7.38 & 76.6 \\
\hline \multirow{2}{*}{\begin{tabular}{|c|}
5 \\
$h r s$
\end{tabular}} & 9 & 0.13 & $* 6.28$ & $* 6.40$ & $* 14.4$ & 3.44 & $* 2.85$ & 73.0 \\
\hline & 10 & 0.09 & $* 4.88$ & $* 4.96$ & $* 10.3$ & 1.91 & $* 2.59$ & $* 80.3$ \\
\hline
\end{tabular}

CL: $95 \%$ confidence limits of the measurements at 3 hours.

Mean: Mean of measurements at 3 hours.

* indicates measurements at 5 hours that are significantly different compared to corresponding $95 \%$ confidence limits of the measurements at 3 hours.

Lymph nodes were not included in the total tracer recovery value because the amount of tracer found in all of the lymph nodes harvested was minimal. (< $0.03 \%$ of total recovery) 


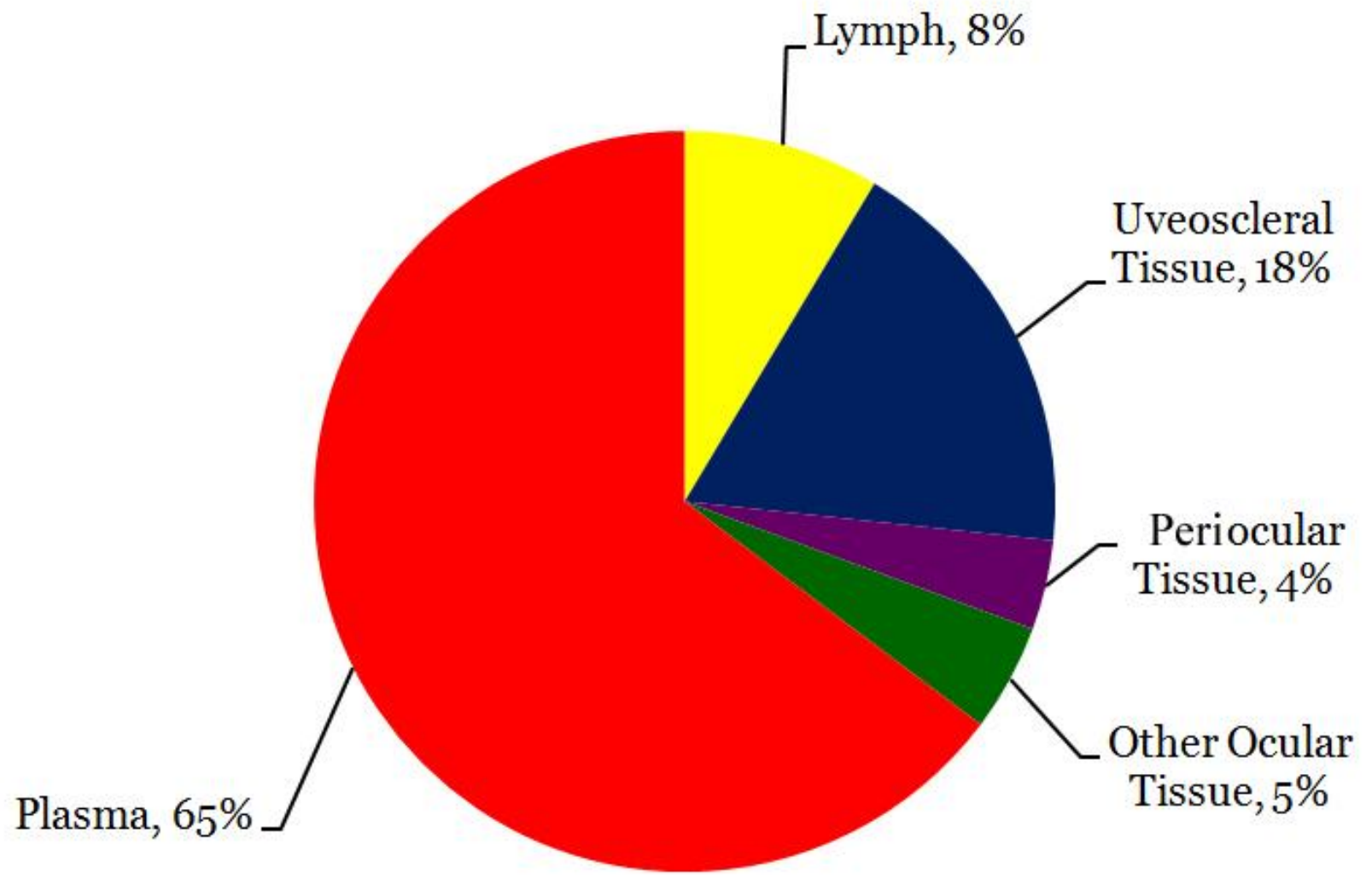

Figure 15. Distribution of tracer recovery before re-filtration corrections ( $n=8,3$ hours) The pie graph shows the mean distribution of tracer recovery before any corrections have been made. When ${ }^{125}$ I-BSA is injected into the anterior chamber, a portion of this will be carried to the systemic circulation, and this will re-circulate into the tissues, which will return to lymph. Thus the tracer recovery in lymph may overestimate recovery. Also this would underestimate plasma tracer recovery. 


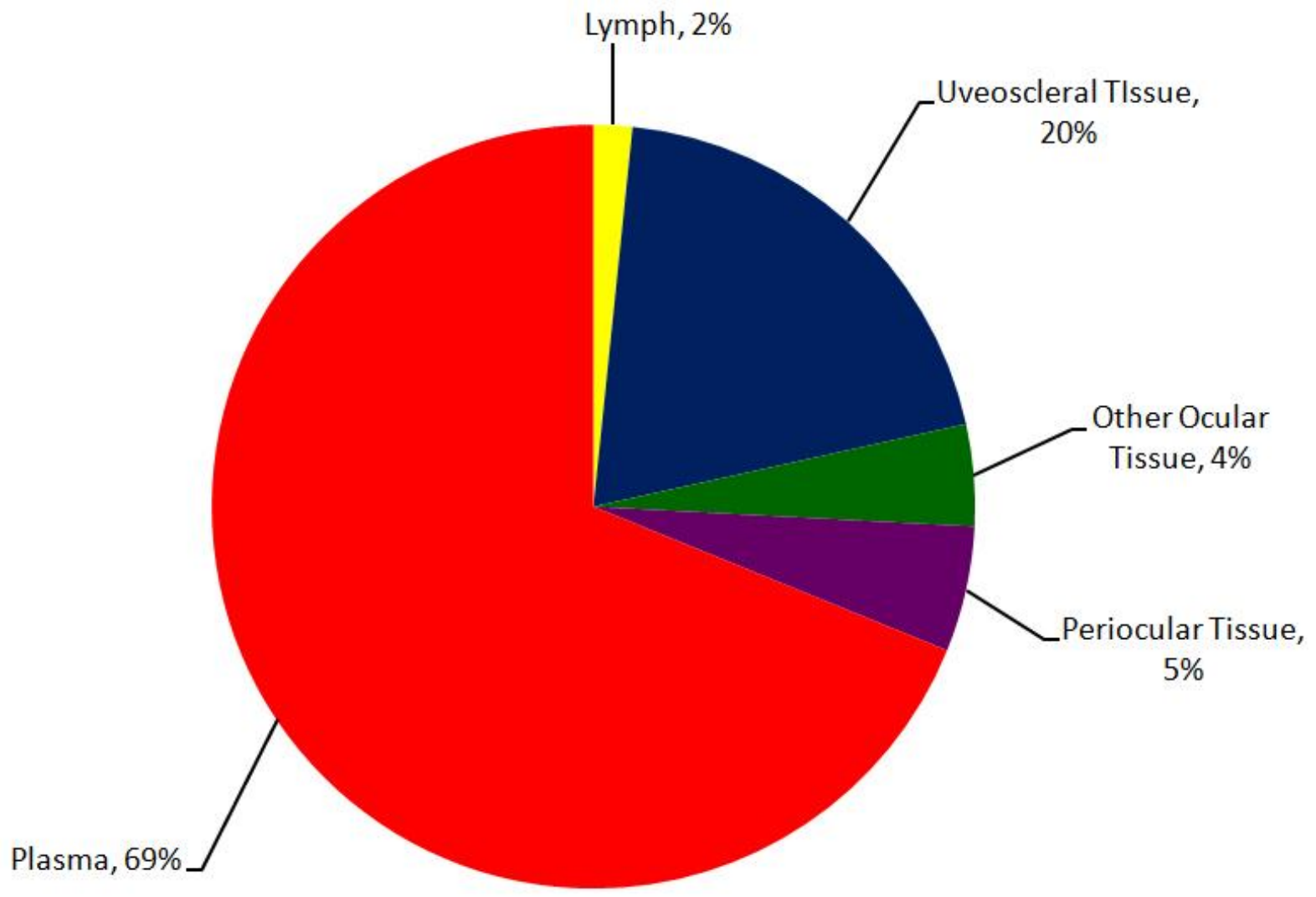

Figure 16. Distribution of Tracer Recovery after re-filtration corrections ( $n=8,3$ hours) The pie graph shows the mean distribution of tracer recovery after re-filtration error has been accounted for. When compared to Figure 15 (pre-correction), tracer recovery in lymph has been decreased from $8 \%$ to $2 \%$, and recovery in plasma has increased from $65 \%$ to $69 \%$. 


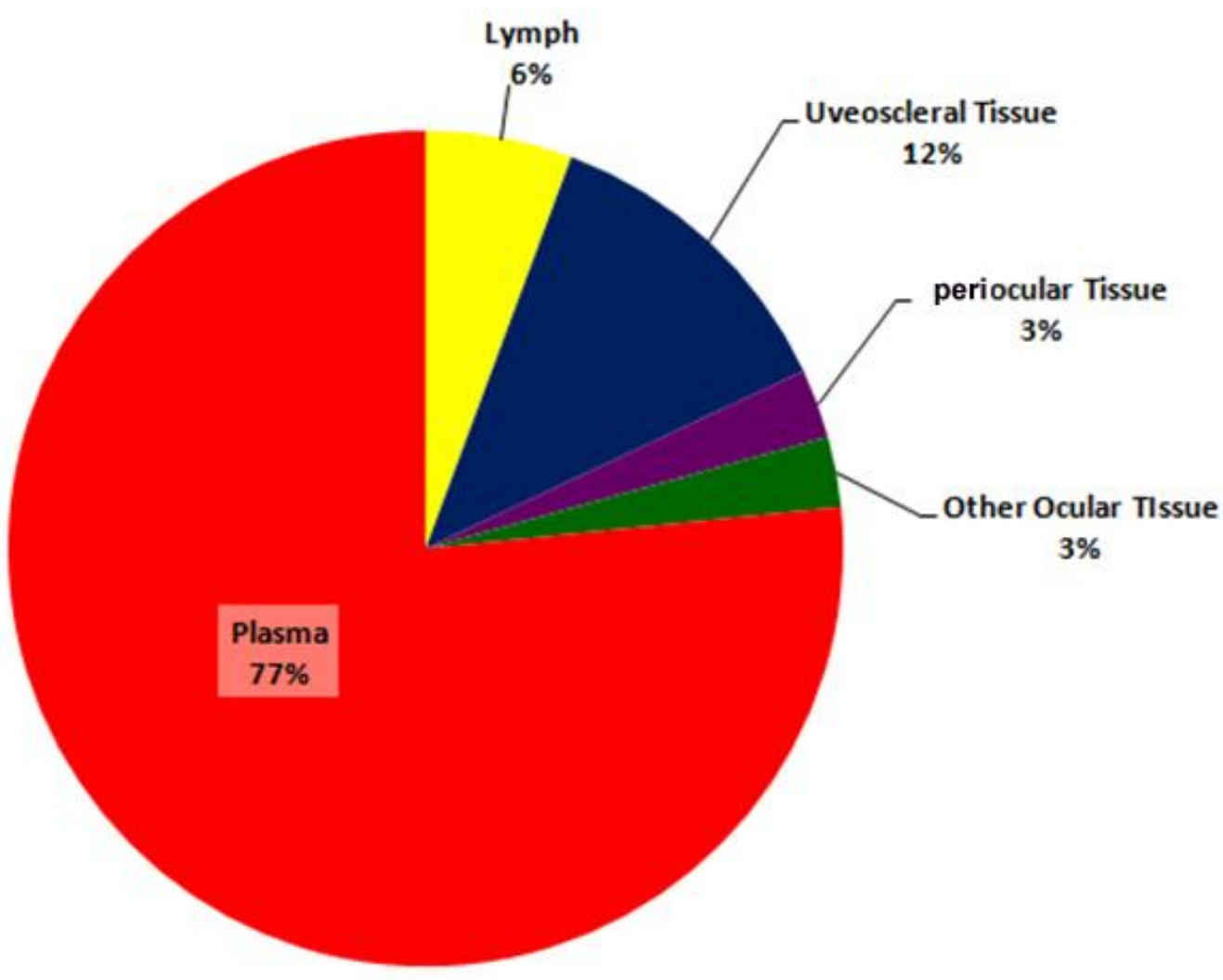

Figure 17. Distribution of Tracer Recovery after re-filtration corrections ( $n=2,5$ hours) The pie graph above shows the mean distribution of tracer recovery at the end of 5 hours, after re-filtration errors have been corrected for. It is important to note the change in proportion of the lymph and uveoscleral tissue compartment when compared to Figure 16, showing the distribution at 3 hours. Tracer recovery in lymph has increased from $2 \%$ to $6 \%$, while recovery in lymph decreased from $20 \%$ to $12 \%$. The data supports the hypothesis that tracer from the anterior chamber is entering the lymphatic system via the lymphatic vessels located within the ciliary body interstitium. 
CHAPTER 4: DISCUSSION 
Chapter 4: Discussion

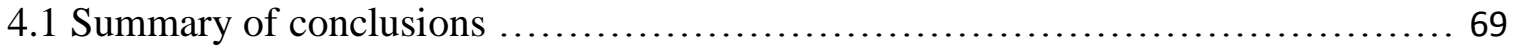

4.2 Drainage of aqueous humor into the lymphatic system ....................... 69

4.3 Limitations and Assumptions .......................................... 71

4.4 Implications: Treatment strategies for Glaucoma (Pharmacology) ................ 73

4.5 Future Directions

4.5.1 Extension of the current experiment ............................... 76

4.5.2 Application to Glaucoma Animal Models .............................. 76

4.5.3 Immunological Perspective ........................................ 78

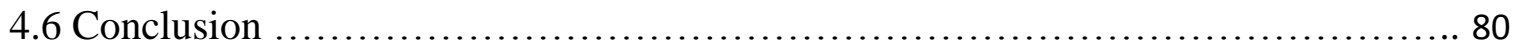




\subsection{Summary of Conclusions}

The present study provides, for the first time in any species, a quantitative demonstration of the contribution of the lymphatic system to aqueous humor drainage. The study also has merit in that it is the first time aqueous humor drainage via the uveoscleral outflow pathway was studied in sheep. The findings indicate that lymphatic drainage from the eye does occur and that it can be measured continuously in sheep.

\subsection{Drainage of aqueous humor into the lymphatic system}

Accumulated evidence has suggested a link between the eye and the lymphatic circulatory system for some time (Gruntzig et al., 1977, 1978a, 1978b, 1979). However, the conventional view was that no lymphatic vessels existed in the eye; a view that can no longer be supported based on recent data (Yücel et al., 2009). Indeed, it is now clear that lymphatic vessels exist in the ciliary body of the human eye and that radioactive protein tracers injected into the aqueous humor in some animals enter the cervical lymphatics in the neck.

Particular attention was focused on the contribution of re-filtration errors in the determination of aqueous humor drainage into blood and lymph. To account for the re-filtration errors, averaged values for lymph protein concentrations and coefficients of protein elimination from plasma were employed, and thus the final values are not exact. Nonetheless, in general terms, we believe that the values determined provide a reasonable view of aqueous humor drainage into the vascular and lymphatic compartments.

While it seems likely that we have underestimated the lymphatic contribution to aqueous humor drainage (see section 4.3), it is clear nonetheless that the majority of the volumetric 
clearance occurs directly into the episcleral veins under baseline conditions. This would seem to be the consensus in the literature. Other investigators have assessed the contributions of conventional and uveoscleral outflow pathways to total outflow by various methods. These include indirect methods such as calculating uveoscleral outflow by subtracting conventional outflow from aqueous flow, and direct methods that involve injecting tracer and calculating the volume of anterior chamber fluid required to have deposited the measured quantity of tracer recovered from the uveoscleral ocular tissue. The ratio of trabecular to uveoscleral outflow in sheep was found to be 69: 22 in our study ( 3 hours). The current study, being the first to quantitatively measure aqueous humor outflow in sheep, there are no previously determined values in the literature. However the 69:22 ratio is comparable to ratios in species such as Cynomolgus monkeys (Bill, 1971), Vervet monkeys (Bill, 1971), mice (Aihara et al., 2003), and dogs (Barrie et al., 1985), whose ratios are 45:55, 62:38, 75:25, and 85:15, respectively. On the other hand, animals with less well-developed ciliary muscles had a considerably reduced amount of uveoscleral flow, such as in rabbits and cats. The 69:22 in sheep is greater than in rabbits and cats, whose ratios are 92-97:3-8 and 97:3, respectively (Bill, 1966a).

To the best of our knowledge, the study reported here is the first to monitor the appearance of a tracer injected into the anterior chamber of the eye in cervical and thoracic duct vessels over time in any species. This approach provides unequivocal support for a lymphatic role in the drainage of aqueous humor. 


\subsection{Limitations and Assumptions}

The lymphatic proportion of drainage is low in comparison with that transported directly into the episcleral veins. However, the anatomy and physiology of the lymphatic system is complex and a number of factors need to be considered. First, a substantial portion of injected protein was found in the uveoscleral tissue at the end of the 3-hour experiments. In the 2 animals where the experiment was extended to 5 hours, tracer recovery decreased in the uveoscleral tissue and increased in the lymph compartment when compared to the 3-hour experiments. Since it seems likely that the tracer from the uveoscleral tissue will most likely enter the lymphatic system, it seems appropriate to consider this part of the lymphatic contribution. If we do so, the uveoscleral/lymphatic drainage contribution to total tracer recovery would amount to approximately $20.83 \pm 0.018 \%$ under baseline conditions.

Second, aqueous outflow may have been altered due to the experimental procedures. Even though the intraocular pressures were similar before and 3 hours after injection, it is likely that there was an immediate elevation in pressure due to the intracameral bolus injection. This pressure increase may have pushed the tracer through the lowest pressure-resistance pathway which would be the conventional route leading to Schlemm's canal and the episcleral veins. The rapid accumulation of tracer in the blood seems to support this contention. In contrast, the tracer accessible to the lymphatic system had to first traverse several (presumably higher resistance), intervening interstitial spaces before being taken up by the vessels. Therefore, the act of injection may have biased the absorption somewhat in favour of the vasculature. Additionally, experimental conditions, such as general anesthesia (Quinn and Shannon, 1975), immobility and mechanical ventilation (Negrini and Moriondo, 2011) would have lead to reductions in lymph flow. 
Third, some of the lymphatic-borne tracer from the eye may have entered the bloodstream directly, thereby bypassing the cervical vessels we had cannulated. This could happen in several ways. Some of the smaller cervical lymphatics that we may not have identified could have delivered tracer into the bloodstream by anastomosing independently with the veins in the neck. Additionally, in previous sheep studies, we identified afferent vessels upstream of our point of cervical vessel cannulation that anastomosed consistently with a local vein (Zakharov et al., 2003.). These vessels would deliver the ${ }^{125}$ I-BSA directly into the bloodstream and would be accounted for in the vascular recovery portion of total recovered tracer. Finally, in our experience the right lymph duct does not exist in most sheep. However, if present, it seems very likely that it would receive a portion of the aqueous humor drained from the right eye. We made no attempt to find or cannulate this vessel and consequently, any tracer entering this duct (if present) would also have been included in the blood recovery data.

In this report, we measured the portion of total aqueous humor drainage that occurred via the lymphatic system using bovine serum albumin as a lymph flow marker. The use of labeled albumin and other proteins as lymph flow markers is well established in the literature. Radiolabeled albumins have been used extensively by the Johnston group for this purpose (Boulton et al., 1997; Boulton, Armstrong et al., 1998; Boulton, Flessner et al., 1998). More than $98 \%$ of the radioactive iodine was bound to BSA prior to injection; however, at the end of the experiment (3hrs/ 5hrs), when precipitated using TCA, the level of bound tracer was found to be at $85-90 \%$. Although not ideal, the unbound ${ }^{125}$ I likely increased the level of radioactivity in all compartments equally. 


\subsection{Implications: Treatment strategies for Glaucoma (Pharmacology)}

Detailed quantitative assessments of trabecular, uveoscleral and lymphatic drainage in sheep are particularly relevant since the recently developed sheep model of glaucoma (Gerometta et al., 2009) has proven useful in developing and testing new IOP-lowering drugs (Gerometta et al., 2010).

Amongst many of the currently available drugs for the treatment of glaucoma, several are believed to exert their beneficial effect (lowering IOP) by increasing the rate of aqueous humor outflow via the uveoscleral outflow pathway. These include the adrenergic and cholinergic drugs. Also, serotoninergic, dopaminergic, adenosinergic and especially prostaglandinergic agents are under investigation (Gabelt and Kaufman, 1995). However, the mechanisms by which the pharmacological approaches affect glaucoma are unknown in many cases.

As mentioned in the introduction, the main site of resistance in the uveoscleral drainage pathway is within the ciliary body. It was also shown that uveoscleral drainage could be influenced by affects on the ciliary muscle tone. Atropine and pilocarpine were the first two cholinergic agents that were shown to influence uveoscleral outflow by affecting the ciliary muscle (Bill, 1967b). Atropine increased the rate of uveoscleral flow in cynomolgus monkeys from 0.90 to $1.07 \mu \mathrm{L} / \mathrm{min}$ (Bill, 1967b). By paralyzing the ciliary muscles, it is used in the treatment for ciliary block glaucoma, and is contraindicated in patients predisposed to narrow angle glaucoma. On the other hand, pilocarpine increases the ciliary muscle tone and significantly slows the uveoscleral flow. It was used in early studies to determine the mechanisms through which prostaglandins reduced IOP. Pretreatment with pilocarpine abolished the effect on IOP and uveoscleral outflow of the naturally occurring prostaglandin $\mathrm{F}_{2 \alpha}\left(\mathrm{PGF}_{2 \alpha}\right)$ in monkeys (Crawford and Kaufman, 1987; Nilsson et al., 1989). These results led to the 
hypothesis that prostaglandins may be lowering IOP initially by mediating the relaxation of the ciliary muscle. It was later shown in vitro that $\mathrm{PGF}_{2 \alpha}$ relaxes the ciliary muscle (Poyer et al., 1995). Once shown in monkeys that $\mathrm{PGF}_{2 \alpha}$ and its analogue (lantanoprost) increases uveoscleral outflow (Gabelt and Kaufman, 1987; Nilsson et al., 1989; Stjernschantz et al., 1998), other prostaglandin analogues were also developed and put into clinical use. The early effects of prostaglandin may be due to the relaxation of ciliary muscle, whereas their long-term effect on IOP may be through a remodeling of the ciliary muscle, resulting in an increased space for outflow. Treatment with $\mathrm{PGF}_{2 \alpha}$ resulted in enlarged spaces between ciliary muscle bundles (Lütjen-Drecoll and Tamm, 1988), which resulted from a deregulation in collagen turnover. Increased metaloproteinases (MMPs) (Lindsey et al., 1996; Weinreb et al., 1997; Ocklind, 1998) and changes in the ciliary muscle cell shape (Stjernschantz et al., 1998) have also been implicated to $\mathrm{PGF}_{2 \alpha}$ treatment. It is clear that prostaglandins have a complex effect on aqueous humor dynamics.

Interestingly, and also in line with the current study, lymphatic vessels respond to a wide variety of biochemical and pharmacological agents (Johnston, 1985), including prostaglandin analogs, which enhance lymphatic drainage (Franzeck et al., 1997; Sinzinger et al., 1997; Amann-Vesti et al., 2003). For example, when the prenodal lymphatic vessels were perfused with added prostaglandins, constriction of the vessels was observed. Moreover, $\mathrm{PGF}_{2 \alpha}$ has also been shown to elicit contractile activity in lymphatic vessels (Johnston et al., 1983; Dabney et al., 1991). Tissue trauma leads to an appearance of prostaglandins in lymph. These compounds may have a direct effect on lymphatic vessels and help modulate lymph flow following injury (Johnston et al., 1979, 1980). Thus one might speculate that the long-term effects of $\mathrm{PGF}_{2 \alpha}$ may be through modulation of the lymphatic vessels that are located within the ciliary body. After its initial impact on ciliary muscle relaxation to allow a greater flow into the ciliary body, a 
stimulation of the lymphatic smooth muscle may further increase uveoscleral drainage of the aqueous humor.

Another class of drugs used for the treatment of glaucoma is the adrenergic agents. Within this family of drugs, epinephrine (adrenaline) has been used in glaucoma therapy for over 100 years; however, the mechanism of action is unclear. It works by stimulating $\alpha_{1}$ - and $\alpha_{2}$ adrenoceptors, as well as $\beta_{2^{-}}$adrenoceptors in the eye and is thought to reduce IOP due to an increase in trabecular (Townsend and Brubaker, 1980; Erickson-Lamy and Nathanson, 1992) and uveoscleral outflow (Schenker et al., 1981; Townsend and Brubaker, 1980). In a study by Bill (1969), epinephrine doubled uveoscleral flow from 0.31 to $0.66 \mu \mathrm{L} / \mathrm{min}$ in vervet monkeys. It is thought that epinephrine may exert its effects by relaxation of the ciliary muscle, since it is a beta-receptor agonist. As in the case with Prostaglandins, adrenaline is also known to increase lymphatic vessel contraction and flow. For example, intravenous infusion of adrenaline was shown to increase the frequency of lymphatic contractions and lymph flow in various lymphatic vessels (popliteal, prefemoral and mesenteric) in conscious sheep (McHale and Roddie, 1983). Thus epinephrine may also be exerting its effect through stimulating lymphatic uptake.

Because there are lymphatic vessels present in the ciliary body, and there is evidence of lymphatic uptake of aqueous humor, it is important to assess whether drugs that target lymphatic, also enhance lymphatic drainage of aqueous humor and lower IOP. Our animal model provides a means for further analysis in this topic, therefore, leading to promises of novel treatments to lower IOP and preserve vision in glaucoma patients. 


\subsection{Future Directions}

\subsubsection{Extension of the Current Experiment}

To strengthen the hypothesis would be to analyze the change in tracer levels in the uveoscleral tissue (iris, ciliary body, choroid, and sclera) and to compare it to the increase of tracer in the lymph samples. The level of tracer recovery in lymph continues to increase at 3 hours, unlike in plasma, where it reaches a plateau around 90 minutes. Also, at the end of 3 hours, when the eye tissue is sampled and analyzed, the level of radioactivity remains high. It may be predicted that the tracer would continue to be carried out from the ciliary body via the lymphatic vessels beyond the 3-hour time point. In order to confirm this hypothesis, the radioactive tracer levels in the uveoscleral tissue can be analyzed at different time points. If the tracer level decreases with time, and this correlates with the increasing levels of tracer found in lymph, it can be reassured that the tracer in lymph did indeed originate from the ciliary body interstitium. The time course analysis and comparison of the changes in tracer levels in the lymph and uveoscleral tissue compartments will also allow us to calculate rate of lymphatic drainage from the ciliary body interstitium.

\subsubsection{Application to Glaucoma Animal Models}

To take this study a step forward, we can create glaucoma models in sheep to determine whether direct targeting of the lymphatic system will be effective in lowering intraocular pressure in glaucoma. As mentioned earlier, there is a recently developed sheep model of glaucoma (Gerometta et al., 2009) that has already been used for developing and testing therapeutics (Gerometta et al., 2010; Gerometta et al., 2010). In humans, it is known that when susceptible, glucocorticosteroid administration may lead to the development of ocular 
hypertension and open-angle glaucoma. It is thought that morphologic and biochemical changes in the trabecular meshwork are associated with the reduction in aqueous humor outflow, which results in a higher IOP (Jones and Rhee, 2006). Gerometta's group (2004) has previously described an in vivo bovine model for steroid induced glaucoma that is reliable and reproducible. When prednisolone acetate was topically applied, it induced IOP elevation in all of the animals tested. More recently the same group developed an ovine model of steroid-induced glaucoma (Gerometta et al., 2009). With a topical application of prednisolone acetate, $100 \%$ of the treated animals exhibited a steroid-induced ocular hypertensive response. This is due to an increased resistance in aqueous outflow (Jones and Rhee, 2006). With cultured trabecular meshwork cells, organ cultured eyes and human specimens were examined, the following mechanisms were proposed: Mechanical changes in the trabecular meshwork structure (Clark et al., 2005), increased deposition of extracellular matrix material, altering the ultrastructure of the outflow pathway (Yue, 1996), decreased breakdown of substances in the trabecular meshwork due to reduced protease activity (Matsumoto and Johnson, 1997; Wordinger and Clark, 1999) and reduction of water flow in the trabecular meshwork (Underwood et al., 1999; Xiong et al., 2005). Since the ovine glaucoma model has been proven to be reliable and reproducible, it would be interesting to assess aqueous humor outflow into the lymphatic system under such conditions. It is possible that under impaired trabecular meshwork outflow; the uveoscleral outflow portion is increased, which would lead to an increased amount of drainage via the lymphatic system. If the conventional outflow into the vascular system is impeded or blocked, it seems reasonable to assume that the uveoscleral-lymphatic pathway will achieve greater prominence in the drainage of aqueous humor.

It is of interest to note in this regard, that there is some evidence that drainage via the uveoscleral-lymphatic route is proportionately enhanced under some conditions. As an example, 
in a monkey study using FITC-dextran 70 as a flow marker, uveoscleral outflow in inflamed eyes was four times that of control eyes (Toris and Pederson, 1987). In addition, prostanoids are used in glaucoma treatment and at least part of their effect appears to reside in the ability to increase drainage by the uveoscleral route. Using indirect methods to assess conventional and unconventional drainage patterns, Prostaglandin F2 alpha or its analogues in humans (Torris et al., 1993) and monkeys (Nilsson et al., 1989; Gabelt and Kaufman, 1989), prostaglandin D2 in rabbits (Goh et al., 1989), and prostaglandin A2 in cats (Torris et al., 1995) increased uveoscleral drainage. Indeed, the intraocular pressure lowering effect of prostaglandin $F_{2} \alpha$ in the cynomolgus monkey was attributed largely to an increase in uveoscleral outflow of aqueous humor, with aqueous outflow being redirected from the trabecular to the uveoscleral route (Gabelt and Kaufman, 1989). It would also be interesting to take the glaucoma model study another step forward and assess whether drainage into the lymphatic system increases with currently available treatments for glaucoma. It would be predicted, again, that for example, $\mathrm{PGF}_{2 \alpha}$ treatment would increase drainage into the uveoscleral eye tissue (the ciliary muscle) and consequently increase lymphatic drainage of the aqueous humor.

\subsubsection{Immunological Perspective}

Another factor to be considered is the concept of immune privilege in the eye. This concept was suggested when transplanted allografts were shown to survive longer in the anterior chamber of the eye compared to 'nonprivileged sites' such as the skin (Medawar, 1948). This immune privilege is thought to be dependent, in part, on the lack of lymphatic drainage with any antigens in the aqueous humor being drained into the trabecular meshwork and into the venous system directly (Streilein 1999, 2003). A phenomenon that has been examined in great detail is the Anterior Chamber acquired immune deviation (ACAID), which describes how an inoculation of 
antigen into the anterior chamber can generate peripheral tolerance. It has been shown in a few studies that antigen presenting cells that have been derived from the eye can be directly drained to the spleen via blood (Wilbanks and Streilein,1990, 1991; Wilbanks et al., 1991). Despite this belief that antigens of the anterior humor can directly drain into the blood without any anatomical lymphatic drainage, it has been demonstrated that soluble antigens reach the lymph nodes in the neck after injections into the anterior chamber (Hoffman et al., 2001; Boonman et al., 2004; Camelo et al., 2006; Yücel et al., 2009). This suggests that the lack of an effective immune response to intraocular antigens is not due to an inability to recognize intraocular antigens, but rather a lack of an effective immune response to develop and persist after antigen recognition or peripheral tolerance.

When Camelo's group injected fluorescent-labeled antigens (dextran, BSA) into the anterior chamber of rats, it was detected in the subcapsular sinus of the right submandibular lymph nodes and cervical lymph nodes (2004). Analysis of the type of antigen baring cells suggests that they were lymphoid organ resident macrophages. The results from this study suggest that antigen leaves the eye predominantly in a soluble form and implies other mechanisms of tolerance may contribute to ocular-specific immune responses. It is possible that the antigens reach the lymph nodes via the lymphatic vessels in the ciliary body, and if so, a manipulation of aqueous humor outflow via this pathway may become useful in creating peripheral tolerance in specific antigens. In the future, taking this study a step further in relation to the immune system may be valuable. 


\subsection{Conclusion}

The data in this report demonstrate unequivocally that proteins injected into the anterior chamber of the eye enter the lymphatic system and after passage through the cervical lymph nodes enter the venous system at the base of the neck. The data in our report and findings from the literature suggest that the lymphatic drainage seems to act as a parallel branch of the uveoscleral pathway. This is the first time that the lymphatic system was studied quantitatively in the context of aqueous humor outflow, and thus adds a valuable new dimension to the outflow pathways, especially in uveoscleral outflow. The study is also valuable in that it is the first time quantitative analysis was done in the drainage of aqueous humor in sheep. As mentioned earlier, there are well established glaucoma models of sheep. Thus, the current study provides a foundation for aqueous humor drainage adapted to glaucoma sheep models. This work stimulates

further study of drug actions on lymphatic outflow from the eye, and may lead to new intraocular pressure lowering treatments to prevent vision loss in glaucoma. 


\section{References}

Adair TH, Guyton AC. Lymph formation and its modification in the lymphatic system. Experimental Biology of the Lymphatic Circulation. Johnston MG Ed. Amsterdam, Elsevier Science Publishers. B.V. 1985: 13-44.

Aihara M, Lindsey JD, Weinreb RN. Aqueous humor dynamics in mice. Invest Ophthalmol Vis Sci 2003; 44(12): 5168-73.

Alm A, Nilsson SF. Uveoscleral outflow- a review. Exp Eye Res 2009; 88(4): 760-8.

Amann-Vesti BR, Gitzelmann G, Koppensteiner R, Franzeck UK. Isoprostane 8-epiprostaglandin F2 alpha decreases lymph capillary pressure in patients with primary lymphedema. J Vasc Res 2003; 40(1): 77-82.

Banerji S, Ni J, Wang SX, Clasper S, Su J, Tammi R, Jones M, Jackson DG. LYVE-1, a new homologue of the CD44 glycoprotein, is a lymph-specific receptor for hyaluronan. J Cell Biol 1999; 144(4): 789-801.

Barrie KP, Gum GG, Samuelson DA, Gelatt KN. Quantification of uveoscleral outflow in normotensive and glaucomatous Beagles by ${ }^{3} \mathrm{H}$-labeled dextran. Am J Vet Res 1985; 46(1): 848.

Becker B. The measurement of rate of aqueous flow with iodide. Invest Ophthalmol 1962; 1: 5208.

Becker B. The decline in aqueous secretion and outflow facility with age. Am J Ophthalmol 1958; 46: 731-36.

Benham GH, Duke-Elder WS, Hodgson TH. The osmotic pressure of the aqueous humour in the normal and glaucomatous eye. J Physiol 1938; 92(3): 355-60. 
Bill A. The aqueous humor drainage mechanism in the cynomolgus monkey (Macaca irus) with evidence for unconventional routes. Invest Ophthalmol 1965; 4: 911-9.

Bill A. Conventional and uveo-scleral drainage of aqueous humour in in the cynomolgus monkey (Macaca irus) at normal and high intraocular pressures, Exp Eye Res 1966a; 5: 45-54.

Bill A. The routes for bulk drainage of aqueous humor in rabbits with and without cyclodialysis Doc. Ophthalmol. 1966b; 20: 157-69.

Bill A. Further studies on the influence of the intraocular pressure on aqueous humor dytnamics in cynomolgus monkeys. Invest Ophthalmol Vis Sci 1967a; 6: 364-72.

Bill A. Effects of atropine and pilocarpine on aqueous humor dynamics in cynomolgus monkeys (Macaca irus). Exp Eye Res 1967b; 6: 120-5.

Bill A. Early effects of epinephrine on aqueous humor dynamics in vervet monkeys (Cercopithecus ethiops). Exp Eye Res 1969; 8:35-43.

Bill A. Aqueous humor dynamics in monkeys (Macaca irus and Cercopithecus ethiops). Exp Eye Res 1971; 11(2): 195-206.

Bill A. Bood circulation and fluid dynamics in the eye. Physiol Rev 1975; 55(3): 383-417.

Bill A, Hellsing K. Production and drainage of aqueous humor in the cynomolgus monkey (Macaca irus). Invest Ophthalmol 1965; 4: 920-6.

Bill A, Phillips CI. Uveoscleral drainage of aqueous humour in human eyes. Exp Eye Res 1971; 12(3): 275-81. 
Bill A, Svedbergh B. Scanning electron microscopic studies of the trabecular meshwork and the canal of Schlemm- an attempt to localize the main resistance to outflow of aqueous humor in man. Acta Ophthalmol (Copenh) 1972; 50(3): 295-320.

Boonman ZF, van Mierlo GJ, Fransen MF, Franken KL, Offringa R, Melief CJ, Jager MJ, Toes RE. Intraocular tumor antigen drains specifically to submandibular lymph nodes, resulting in an abortive cytotoxic T cell reaction. J Immunol 2004; 172(3): 1567-74.

Boulanger B, Yuan Z, Flessner M, Hay J, Johnston M. Pericardial fluid absorption into lymphatic vessels in sheep. Microvasc Res 1999; 57(2): 174-86.

Boulton M, Armstrong D, Flessner M, Hay J, Szalai JP, Johnston M. Raised intracranial pressure increases CSF drainage through arachnoid villi and extracranial lymphatics. Am J Physiol 1998; 275(3 Pt 2): R889-96.

Boulton M, Flessner M, Armstrong D, Hay JB, Johnston M. Lymphatic drainage of the CNS: Effects of lymphatic diversion/ligation on CSF protein transport to plasma. Am J Physiol 1997; 272: R1613-9.

Boulton M, Flessner M, Armstrong D, Hay J, Johnston M. Determination of volumetric cerebrospinal fluid absorption into extracranial lymphatics in sheep. Am J Physiol 1998; 274: R88-96

Bradbury MWB, Cole DF. The role of the lymphatic system in drainage of cerebrospinal fluid and aqueous humor. J Physiol 1980; 299: 353-65.

Brubaker RF. Determination of episcleral venous pressure in the eye. A comparison of three methods. Arch Ophthalmol 1967; 77(1): 110-4.

Brubaker RF. Clinical measurements of aqueous dynamics: implication for addressing glaucoma. In: Cican MM, Ed. The eye's aqueous humor from secretion to glaucoma. New York: Academic Press 1998. 
Burgoyne CF, Downs JC, Bellezza AJ, Suh JK, Hart RT. The optic nerve head as a biomechanical structure: a new paradigm for understanding the role of IOP-related stress and strain in the pathophysiology of glaucomatous optic nerve head damage. Prog Retin Eye Res 2005; 24: 39-73.

Camelo S, Kezic J, Shanley A, Rigby P, McMenamin PG. Antigen from the anterior chamber of the eye travels in a soluble form to secondary lymphoid organs via lymphatic and vascular routes. Invest Ophthalmol Vis Sci 2006; 47(3): 1039-46.

Camelo S, Shanley A, Voon A, McMenamin PG. The distribution of antigen in lymphoid tissues following the injection into the anterior chamber of the rat eye. The journal of Immunology 2004; 172: 5388-95.

Civan MM, Macknight AD. The ins and outs of aqueous humor secretion. Exp Eye Res. 2004; 78(3): 155-62.

Clark AF, Brotchie D, Read AT, Hellberg P, English-Wright S, Pang IH, Ethier CR, Grierson I. Dexamethasone alters F-actin architecture and promotes cross-linked actin network formation in human trabecular meshwork tissue. 2005; 60(2): 83-95.

Coca-Prados M, Sanchez-Torres J. Molecular approaches to the study of the $\mathrm{Na}^{+}-\mathrm{K}^{+}$-ATPase and chloride channels in the ocular ciliary epithelium. In:Vivan MM, editor. The eye's aqueous humor. San Diego: Academic Press 1998.

Colasanti BK. Aqueous humor dynamics in the enucleated deer eye. Comp Biochem Physiol A Comp Physiol 1984; 78(4): 755-6.

Cole DF. Secretion of the aqueous humour. Exp Eye Res 1977; 25(suppl): 161-76.

Cole DF, Monro PAG. The use of fluorescein-labelled dextrans in investigation of aqueous humor outflow in the rabbit. Exp Eye Res 1976; 23: 571-85. 
Collin HB. Lymphatic drainage of ${ }^{131} \mathrm{I}$ - albumin from the vascularized cornea. Invest Ophthalmol 1970; 9: 146-55.

Conrad JM, Robinson JR. Aqueous chamber drug distribution volume measurement in rabbits. J Pharm Sci 1977; 66(2): 219-24.

Crawford K, Kaufman PL, Pilocarpine antagonists prostaglandin F2 alpha-induced ocular hypotension in monkeys. Evidence for enhancement of Uveoscleral outflow by prostaglandin F2 alpha. Arch Ophthalmol 1987; 105: 112-6.

Cserr HF, Knopf PM, Cervical lymphatics, the blood-brain barrier and the immunoreactivity of the brain: a new view. Immunology Today 1992; 13: 507-12.

Dabney JM, Buehn MJ, Dobbins DE. Perfused prenodal lymphatics are constricted by prostaglandins. Am J Physiol 1991; 260(1 pt 2): H1-5.

Erickson-Lamy KA, Nathanson JA. Epinephrine increases facility of outflow and cyclic AMP content in the human eye in vitro. Invest Ophthalmol Vis Sci 1992; 33(9): 2673-8.

Ethier CR, Kamm RD, Palaszewski BA, Johnson MC, Richardson TM. Calculations of flow resistance in the juxtacanalicular meshwork. Invest Opthalmol Vis Sci 1986; 27(12): 1741-50.

Epstein DL, Rohen JW. Morphology of the trabecular meshwork and inner-wall endothelium after cationized ferritin perfrusion in the monkey eye. Invest Ophthalmol Vis Sci 1991; 32(1): $160-71$.

Foster PJ, Buhrmann F, Quigley HA, Johnson GJ. The definition and classification of glaucoma in prevalence surveys. Br J Ophthalmol 2002; 86: 238-42.

Flessner MF, Dedrick RL, Schultz JS. A distributed model of peritoneal-plasma transport: theoretical considerations. Am J Physiol 1984; 246: R597-607 
Flessner MF Dedrick RL, Schultz JS A distributed model of peritoneal-plasma transport: analysis of experimental data in the rat. Am J Physiol 1985; 248: F413-424.

Flessner MF, Dedrick RL, Reynolds JC. Bidirectional peritoneal transport of immunoglobulin in rats: compartmental kinetics. Am J Physiol 1992; 262: F275-287.

Franzeck UK, Spiegel I, Fischer M, Börtzler C, Stahel HU, Bollinger A. Combined physical therapy for lymphedema evaluated by fluorescence microlymphography and lymph capillary pressure measurements. J Vasc Res 1997; 34(4): 306-11.

Gaasterland DE, Pederson JE, MacLellan HM, Reddy VN. Rhesus monkey aqueous humor composition and a primate ocular perfusate. Invest Ophthalmol Vis Sci 1979; 18(11): 1139-50.

Gabelt BT, Kaufman PL. Prostaglandin F2 alpha increases uveoscleral outflow in the cynomolgus monkey. Exp Eye Res 1989; 49(3): 389-402.

Gabelt BT, Kaufman PL. Aqueous humor hydrodynamics. In: Kaufman PL, Alm A, Ed. Alder's physiology of the eye, Vol 8. St. Louis, MO Mosby; 1995; 237-289.

Gabelt BT, Kaufman PL. Aqueous humor hydrodynamics. In: Kaufman PL, Alm A, Ed. Adler's Physiology of the Eye Clinical Application, $10^{\text {th }}$ ed. St. Louis, MO: Mosby; 2003; 293-316.

Gerometta R, Alvarez LJ, Candia OA. Effects of sildenafil and tadalafil on intraocular pressure in sheep: implications for aqueous humor dynamics. Invest Ophthalmol Vis Sci 2010; 51(6): 3139-44.

Gerometta, RM, Malgor LA, Vilalta E, Leiva J, Candia OA. $\mathrm{Cl}^{-}$concentrations of bovine, procine and ovine aqueous humor are higher than in plasma. Exp Eye Res 2005; 80(3): 307-12. 
Gerometta R, Podos SM, Candia OA, Wu B, Malgor LA, Mittag T, Danias J. Steroid-induced ocular hypertension in normal cattle. Arch Ophthalmol 2004; 122: 1492-7.

Gerometta R, Podos SM, Danias J, Candia OA. Steroid-induced ocular hypertension in normal sheep. Invest Ophthalmol Vis Sci 2009; 50(2): 669-73.

Gerometta R, Spiga MG, Borrás T, Candia OA. Treatment of sheep steroid-induced ocular hypertension with a glucocorticoid-inducible MMP1 gene therapy virus. Invest Ophthalmol Vis Sci 2010; 51(6): 3042-8.

Grant WM. Tonographic method for measuring the facility and rate of aqueous flow in human eyes. Arch Ophthal 1950; 44(2) : 204-14.

Green K, Sherman SH, Laties AM, Pederson JE, Gaasterland DE, MacLellan HM. Fate of anterior chamber tracers in the living rhesus monkey eye with evidence for uveo-vortex outflow. 1977; 97(4) : 731-9.

Greenbaum S, Lee PY, Howard-Williams J, Podos SM. The optically determined corneal and anterior chamber volumes of the cynomolgus monkey. Curr Eye Res 1985; 4(3) : 187-90.

Grierson I, Lee WR. Pressure effects on flow channels in the lining endothelium of Schlemm's canal. A quantitative study by transmission electron microscopy. Acta Ophthalmol (Copenh) 1978; 56(6): 935-52.

Gruntzig J, Kiem J, Becker V, Schwarzhoff V, Feinendegen LE, Schicha H. Drainage of the radioactive lymphotropic tracers 198 Au-colloid and 99m Tc-sulfur colloid from the orbit in rabbits. Albrecht Von Graefes Arch Klin Exp Ophthalmol 1977; 204: 161-75.

Gruntzig J, Schicha H, Kiem J, Becker V, Feinendegen LE. Studies on the lymph drainage of the eye 5. Quantitative registration of the lymph drainage from the subconjunctival space with a radioactive tracer. Klin Monatsbl Augenheikd 1978a; 172: 872-6 
Gruntzig J, Schicha H, Becker V, Kiem J, Feinendegen LE. Studies on the lymph drainage of the eye 4. Drainage of lymphotropic radioactive tracers (99mTc-Microcolloid) after intravitreal injection. Klin Monatsbl Augenheikd 1978b; 172: 87-94.

Gruntzig J, Schicha H, Huth F. Eye and lymph drainage. Z Lymphol 1979; 3: 35-45.

Gruntzig J, Schicha H, Kiem J, Becker V, Feinendegen LE. Studies on the lymph drainage of the eye 5. Quantitative registration of the lymph drainage from the subconjunctival space with radioactive tracer. Klin Monatsbl Augenheilkd 1978a; 172: 872-6.

Goldman HA. Minute Volume and WIderstand der Kammerwasserstromung des Menschen. Doc Ophthalmol 1951; 5-6: 278-356.

Guyomard JL, Rosolen SG, Paques M, Delyfer MN, Simonutti M, Tessier Y, Sahel JA, Legargasson JF, Picaud S. A low-cost and simple imaging technique of the anterior and posterior segments: eye fundus, ciliary bodies, iridocorneal angle. Invest Ophthalmol Vis Sci. 2008; 49(11): 5168-74.

Haddad A, Laicine EM, de Almeida JC. Origin and renewal of the intrinsic glycoproteins of the aqueous humor. Graefes Arch Clin Exp Ophthalmol 1991; 229(4): 371-9.

Helbig H, Korbmacher C, Wohlfarth J, Berweck S, Kuhner D, Wiederholt M, Electrogenic Na+ascorbate cotransport in cultured bovine pigmented ciliary epithelial cells. Am J Physiol 1989; 256: C44-9.

Hoffman F, Zhang E-P, Mueller A, Schulte F, Foss H-S, Franke J, Coupland SE. Contribution of lymphatic drainage system in corneal allograft rejection in mice. Graefe's Arch. Clin Exp Ophthalmol 2001; 239: 850-8.

Inomata H, Bill A, Smelser GK. Aqueous humor pathways through the trabecular meshwork and into Schlemm's canal in the cynomolgus monkey (Macaca irus). An electron microscopic study. Am J Opthalmol 1972; 73(5): 760-89. 
Johnson CA, Keltner JL, Celo KE, Edwards M, Kass MA, Gordon MO, Budenz DL, Gaasterland DE, Werner E; Ocular Hypertension Study Group. Baseline Visual Field Characteristics in the ocular hypertension treatment study. Ophthalmol. 2002; 109(3): 432-7.

Johnson M, Erickson K. Mechanisms and routes of aqueous humor drainage. In: Albert DM, Jakobiec FA, Eds. Principles and practice of ophthalmology, Philadelphia: WB Saunders 2000.

Johnson SB, Coakes RL, Brubaker RF, A simple photogrammetric method of measuring anterior chamber volume. Am J Ophthalmol 1978; 85: 469-474.

Johnston MG, Hay JB, Movat HZ. Kinetics of prostaglandin production in various inflammatory lesions, measured in draining lymph. Am J Pathol 1979; 95: 225.

Johnston MG, Hay JB, Movat HZ. The distribution of prostaglandins in afferent and efferent lymph from inflammatory sites. Am J Pathol 1980; 99: 695.

Johnston MG, Kanalec A, Gordon JL. Effects of arachidonic acid and its cyclo-oxygenase and lipooxygenase products on lymphatic vessel contractility in vitro. Prostaglandins 1983; 25(1): $85-98$.

Johnston MG. Involvement of lymphatic collecting ducts in the physiology and pathophysiology of lymph flow. In: Experimental Biology of the lymphatic circulation, ed. Johnston MG. New York: Elsevier Science Publishers, 1985, pp. 81-210.

Johnston M, Zakharov A, Papaiconomou C, Salmasi G, Armstrong D. Evidence of connections between cerebrospinal fluid and nasal lymphatic vessels in humans, non-human primates and other mammalian species. Cerebrospinal Fluid Res 2004; 1(1):2

Johnston M, Zakharov A, Koh L, Armstrong D. Subarachnoid injection of Microfil reveals connections between cerebrospinal fluid and nasal lymphatics in the non-human primate. Neuropathol Appl Neurobiol 2005; 31: 632-40. 
Jones R 3rd, Rhee DJ. Corticosteroid-induced ocular hypertension and glaucoma: a brief review and update of the literature. Curr Opin Ophthalmol 2006; 17:163-7.

Kahn HJ, Marks A. A new monoclonal antibody, D2-40, for detection of lymphatic invasion in primary tumors. Lab Invest 2002; 82: 1255-7.

Kempster RC, Bancroft BJ, Hirst LW. Intraorbital anatomy of the koala (phascolarctos cinereus). Anat Rec 2002; 267: 277-87.

Kinsey VE. The chemical composition and the osmotic pressure of the aqueous humor and plasma of the rabbit. J Gen Physiol 1951; 34(3): 389-402.

Kinsey VE. Comparative chemistry of aqueous humor in posterior and anterior chambers of rabbit eye, its physiologic significance. AMA Arch Ophthalmol 1953; 50(4): 401-17

Kondo T, Miura M, Imamichi M. Measurement method of the anterior chamber volume by image analysis. Br J Ophthalmol 1986; 70(9): 668-72.

Krohn J, Bertelsen T. Corrosion casts of the suprachoroidal space and uveoscleral drainage routes in the human eye. Acta Ophthalmol Scand 1977: 75(1): 32-5.

Krohn J, Rodahl E. Expression of 5'-nucleotidase and alkaline phosphatase in human aqueous drainage channels. Acta Opthalmol Scand 2002; 80: 642-51.

Krupin T, Civan MM. The physiologic basis of aqueous humor formation. In: Ritch R, Shields MB, Krupin T Ed. The Glaucomas. Mosby, St. Louis: 251-80.

Krupin T, Wax M, Moolchandani J. Aqueous production. Trans Ophthalmol Soc UK 1986; 105: $156-61$. 
Kwon YH, Fingert JH. Primary open-angle glaucoma. N Engl J Med 2009; 360(11): 1113-24.

Labiris G, Gkika M, Katsanos A, Fanariotis M, Alvanos E, Kozobolis V. Anterior chamber volume measurements with Visante optical coherence tomography and Pentacam: repeatability and level of agreement. Clin Exp Ophthalmol 2009; 37(8): 772-4.

Levene RZ. Osmolarity in the normal state and following acetazolamide. AMA Arch Ophthalmol 1958; 59(4): 597-602.

Lindsey JD, Kashiwaqi K, Boyle D, Kashiwaqi F, Firestein GS, Weinreb RN. Prostaglandins increase pro MMP-1 and pro MMP-3 secretion by human ciliary smooth muscle cells. Curr Eye Res. 1996; 15(8): 869-75.

Lütjen-Drecoll E, Tamm E. Morphological study of the anterior segment of cynomolgus monkey eyes following treatment with prostaglandin F2 alpha. Exp Eye Res. 1988; $147(5)$ : 761-9.

Macri FJ, Cervario SJ. The dual nature of pilocarpine to stimulate or inhibit the formation of aqueous humor. Invest Ophthalmol 1974; 13(8): 617-9

Macri FJ, Dixon RL, Rall DP. Aqueous humor turnover rates in the cat. I. Effect of acetazolamide. Invest Ophthalmol 1965; 4(5): 927-34.

Mark HH. Aqueous humor dynamics in historical perspective. Surv Ophthalmol 2009; 55(1): 89100.

Matsumoto Y, Johnson DH. Dexamethasone decreases phagocytosis by human trabecular meshwork cell sin situ. Invest Ophthalmol Vis Sci. 1997; 38: 1902-07.

McHale NG, Roddie IC. The effect of intravenous adrenaline and noradrenaline infusion of peripheral lymph flow in the sheep. J Physiol 1983; 341: 517-26. 
McMaster PR, Macri FJ. Secondary aqueous humor outflow pathways in the rabbit, cat and monkey. Arch Ophthalmol 1968; 79(3): 297-303.

McMenamin PG, Steptoe RJ. Normal anatomy of the aqueous humor outflow system in the domestic pig eye. J Anat 1991; 178: 65-77.

Medawar PB. Immunity to homologous grafted skin; the fate of skin homografts transplanted to the brain, to subcutaneous tissue, and to the anterior chamber of the eye. Br J Exp Pathol 1948; 19: 58.

Millar C and Kaufman PL. Aqueous humor: secretion and dynamics. In: Tasman W, Jaeger EA, Eds. Duane's foundations of clinical ophthalmology. Philadelphia: Lippincott-Raven 1995.

Mizuno R, Koller A, Kaley G. Regulation of the vasomotor activity of lymph microvessels by nitric oxide and prostaglandins. Am J Physiol Regul Integr Comp Physiol 1998; 85(1): 35-42.

Mollangji R, Bozanovic-Sosic R, Silver I, Li B, Kim C, Midha R, Johnston MG. Intracranial pressure accommodation is impaired by blocking pathways leading to extracranial lymphatics. Am J Physiol 2001; 2809: R1573-R1581.

Negrini D, Moriondo A. Lymphatic Anatomy and Biomechanics. J Physiol 2011 Apr 11 [Epub ahead of print]

Nilsson SFE, Bill A. Pyhsiology and neurophysiology of aqueous humor inflow and outflow, In: Kaufma PL, Mittag TW, Eds, Glaucoma. Mosby-Year Book Europe Ltd., 1994.

Nilsson SF, Samuelsson M, Bill A, Stjernschantz J. Increased uveoscleral outflow as a possible mechanism of ocular hypotension casued by prostaglandin F2 alpha-1-isopropylester in the cynomolgus monkey. Exp Eye Res 1989; 48(5): 707-16.

Ocklind A. Effect of latanoprost on the extracellular matrix of the ciliary muscle: a study on cultured cells and tissue sections. Exp Eye Res 1998; 67: 179-91. 
O'Rourke J, Macri FJ. Studies in uveal physiology. II. Clinical studies of the anterior chamber clearance of isotopic tracers. Arch Ophthalmol 1970; 84(4): 415-20.

Papaiconomou C, Zakharov A, Azizi N, Djenic J, Johnston M. Reassessment of the pathways responsible for cerebrospinal fluid absorption in the neonate. Child's Nervous System 2004; 20 : 29-36.

Papaiconomou C, Zakharov A, Bozanovic-Sosic R, Johnston M. Does neonatal cerebrospinal fluid absorption occur via arachnoid projections or extracranial lymphatics? Am J Physiol 2002; 283: R869-76

Passaglia CL, Guo X, Chen J, Troy JB. Tono-Pen XL calibration curves for cats, cows and sheep. Vet Ophthalmol 2004; 7(4): 261-4.

Pederson JE, Gaasterland DE, Maclellan HM. Anterior chamber volume determination in the rhesus monkey. Invest Ophthalmol Vis Sci. 1978; 17(8): 784-7.

Phelps CD, Armaly MF. Measurement of episcleral venous pressure. Am J Ophthalmol 1978; 85(1): 35-42.

Phillips MJ, Needham M, Weller RO. Role of the cervical lymph nodes in autoimmune encephalomyelitis in the Lewis rat. JPathol 1997; 182: 457-64.

Poyer JF, Millar C, Kaufman PL. Prostaglandin F2 alpha effects on isolated rhesus monkey cilary muscle. Invest Ophthalmol Vis Sci 1995; 54: 277-83.

Quigley HA, Broman AT. The number of people with glaucoma worldwide in 2010 and 2020 . Br J Ophthalmol 2006; 90(3): 262-7 
Quin JW, Shannon AD. The effect of anesthesia and surgery on lymph flow, protein and leucocyte concentration in lymph of the sheep. Lymphology 1975; 8(4): 126-35.

Reddy VN. Dynamics of transport systems in the eye. Invest Ophthalmol Vis Sci 1979; 18: 1000.

Reiss GR, Werness PG, Zollman PE, Brubaker RF. Ascorbic acid levels in the aqueous humor of nocturnal and diurnal mammals. Arch Ophthalmol 1986; 104(5): 753-5.

Riley MV, Kishida K. ATPase of ciliary epithelium: cellular and subcellular distribution and probable role in secretion of aqueous humor. Exp Eye Res 1986; 42: 559-68.

Schenker HI, Yablonski ME, Podos SM, Linder L. Fluorophotometric study of epinephrine and timolol in human subjects. Arch Ophthalmol 1981; 99(7): 1212-6.

Schottenstein EM. Intraocular pressure. In: Ritch R, Shields MB, Krupin T, Eds. The glaucomas. St. Louis: Mosby 1989; pp. 301-17.

Seiler T, Wollensak J. The resistance of the trabecular meshwork to aqueous humor outflow. Graefes Arch Clin Exp Ophthalmol 1985; 223(2): 88-91.

Sears ML. The aqueous In: Moses RA, Ed. Adler's physiology of the eye, $7^{\text {th }}$ ed. St. Louis, MO: Mosby 1981.

Simones P, De Geest JP, Lauwers H. Comparative morphology of the pectinate ligaments of domestic mammals as observed under the dissecting microscope and the scanning electron microscope. J Vet Med Sci 1996; 58(10): 977-82.

Sinzinger H, Oguogho A, Kaliman J. Isoprostane 8-epi-prostaglandin F2 alpha is a potent contractor of human peripheral lymphatics. Lymphology 1997; 30(3): 155-9. 
Sires B. Orbital and ocular anatomy. In: Wright, Ed. Textbook of Ophthalmology. Baltimore, MD: Williams and Wikins 1997.

Stjernschantz J, Selén G, Ocklind A, Resul B. Effects of latanoprost and related prostaglandin analogues In: Alm A, Weinreb RN (Eds), Uveoscleral Outflow. Biology and clinical Aspects. Mosby-Wolfe Medical Communications, London, 1998 pp. 57-72.

Streilein JW. General principles of immune-ophthalmology. Dev Ophthalmol. 1999; 30: 1-23.

Streilein JW. Ocular immune privilege: the eye takes a dim but practical view of immunity and inflammation. J Leuko BIol 2003; 74(2): 179-85.

Toris CB. Aqueous humor dynamics I. Current Topics in Membranes, The Eye's Aqueous Humor Ed 2. Civan MM. San Diego, Academic Press 2008; 62: 193-229.

Toris CB, Lane JT, Akagi Y, Blessing KA, Kador PF. Aqueous flow in galactos-fed dogs. Exp Eye Res 2006; 83(4): 865-70.

Toris CB, Pederson JE. Effect of intraocular pressure on uveoscleral outflow following cyclodialysis in the monkey eye. Invest Ophthalmol Vis Sci. 1985; 26: 1745-9.

Toris, C.B., Yablonski, M.E., Wang, Y.-L., Camras, C.B., Aqueous humor dynamics in the aging human eye. Am. J. Ophthalmol. 1999; 127: 407-412.

Tornquist P, Alm A, Bill A. Permeability of ocular vessels and transport across the blood-retinalbarrier. Eye 1990; 4(Pt 2): 303-9.

Townsend DJ, Brubaker RF. Immediate effect of epinephrine on aqueous formation in the normal human eye as measured by fluorophotometry. Invest Ophthalmol Vis Sci 1980; 19(3): 256-66. 
Underwood JL, Murphy CG, Chen J, Franse-Carman L, Wood I, Epstein DL, Alvarado JA. Glucocorticoids regulate transendothelial fluid flow resistance and formation of intercellular junctions. Am J Physiol. 1999; 277: C330-342.

Uusitalo R, Palkama A, Stjernschantz J. An electron microscopical study of the blood-aqueous barrier in the ciliary body and iris of the rabbit. Exp Eye Res 1973; 17(1): 49-63.

Vadillo-Ortega F, Gonzalez-Avila G, Chevez P, Abraham CR, Montano M, Selman-Lama M. A latent collagenase in human aqueous humor. Invest Ophthalmol Vis Sci 1989; 30(2): 332-5.

Wang RF, Lee PY, Taniguchi T, Becker B, Podos SM, Serle JB, Mittaq TW. Effect of oxymetazoline on aqueous humor dynamics and ocular blood flow in monkeys and rabbits. Arch Ophthalmol. 1993;111:535-538.

Wang YL, Toris CB, Zhan G, Tablonski ME. Effects of topical epinephrine on aqueous humor dynamics in the cat. Exp Eye Res. 1999;68: 439-445.

Ward, D.A., Cawrse, M.A., Hendrix, D.V.H., 2001. Fluorophotometric determination of aqueous humor flow rate in clinically normal dogs. Am. Vet. Res. 62, 853e858.

Weinreb RN. Uveoscleral outflow: the other ocular pathway. J Glaucoma 2000; 9(5): 343-5.

Weinreb RN, Kashiwaqi K, Kashiwaqi F, Tsukahara S, Lindsey JD. Prostaglandins increase matrix metalloproteinase release from human ciliary smooth muscle cells. Invest Ophthalmol Vis Sci. 1997; 38(13): 2772-80.

Weller RO. Pathology of cerebrospinal fluid and interstitial fluid of the CNS: significance for Alzheimer disease, prion disorders and multiple sclerosis. J Neuropathol Exp Neurol 1998; 57: 885-94. 
Willbanks GA, Mammolenti M, Streilein JW. Studies on the induction of anterior chamberassociated immune deviation (ACAID). II. Eye-derived cells participate in generating bloodborne signals that induce ACAID. J Immunol 1991; 146:3018.

Willbanks GA, Streilein JW. Characterization of suppressor cells in anterior chamber-associated immune deviation (ACAID) induced by soluble antigen: evidence of two functionally and phenotypically distinct T-suppressor cell populations. Immunology 1990; 71: 383

Willbanks GA, Streilein JW. Studies on the induction of anterior chamber-associated immune deviation (ACAID).1 Evidence that an antigen-specific, ACAID-inducing, cell-associated signal exists in the peripheral blood. J Immunol 1991; 146: 2610.

Wordinger RJ, Clark AF. Effects of glucocorticoids on the trabecular meshwork: towards a better understanding of glaucoma. Prog Retin Eye Res. 1999; 18: 629-667.

Xiong X, Miao J, Xi Z, Zhang H, Han B, Hu Y. Regulatory effect of dexamethasone on aquaporin-1 expression in cultured bovine trabecular meshwork cells. J Huazhong Univ Sci Technolog Med Sci. 2005; 25: 735-7.

Yablonski, M.E., Zimmerman, T.J., Waltman, S.R., Becker, B. A fluorophotometric study of the effect of topical timolol on aqueous humor dynamics. Exp. Eye Res. 1978; 27: 135-142.

Yücel YH, Johnston MG, Ly T, Patel M, Drake B, Gümüs E, Fraenkl SA, Moore S, Tobbia D, Armstrong D, Horvath E, Gupta N. Identification of lymphatics in the ciliary body of the human eye: a novel "uveolymphatic" outflow pathway. Exp Eye Res 2009; 89(5): 810-9.

Yue BY. The extracellular matrix and its modulation in the trabecular meshwork. Surv Ophthalmol 1996; 40: 379-90.

Zakharov A, Papaiconomou C, Djenic J, Midha R, Johnston M. Lymphatic cerebrospinal fluid absorption pathways in neonatal sheep revealed by subarachnoid injection of Microfil. Neuropathol Appl Neurobiol 2003; 29(6): 563-73. 
Zakharov A, Papaiconomou C, Koh L, Djenic J, Bozanovic-Sosic R, Johnston M. Integrating the roles of extracranial lymphatics and intracranial veins in cerebrospinal fluid absorption in sheep. Microvasc Res 2004; 67: 96-104. 